\title{
Wirtschaftliche Schocks
}

\author{
- ANALYSE \\ Die Wirtschaft der »Festung Russland« - kurzfristig erfolgreich im Corona- und \\ Sanktionsumfeld, langfristig mehr Stagnation und Sanktionen \\ Gunter Deuber (Raiffeisen Bank International AG, Wien) \\ STATISTIK \\ Russlands Wirtschaft - \\ Covid-19, Entwicklung und Prognosen \\ ANALYSE \\ Russische kleine und mittlere Unternehmen (KMUs) in der Corona-Krise - \\ Ein Sterben auf Raten \\ Michael Martin Richter \\ (Forschungsstelle Osteuropa an der Universität Bremen) \\ STATISTIK \\ Covid-19 in Russland, Stand 24. Juni 2021 \\ CHRONIK \\ Covid-19-Chronik, 03. - 30. Mai 2021 \\ CHRONIK \\ 17. Mai - 10. Juni 2021

Deutsches

Polen-Institut
Forschungsstelle Osteuropa an der Universität Bremen
Leibniz-Institut für

Agrarentwicklung in

Transformationsökonomien
Leibniz-Institut für Ost- und Südosteuropa-

forschung
Zentrum für Osteuropa- und internationale Studien (ZOiS) $\mathrm{gGmbH}$ 


\title{
Die Wirtschaft der "Festung Russland « - kurzfristig erfolgreich im Corona- und Sanktionsumfeld, langfristig mehr Stagnation und Sanktionen
}

\author{
Gunter Deuber (Raiffeisen Bank International AG, Wien)
}

DOI: $10.31205 /$ RA.404.01

\section{Zusammenfassung}

In den Jahren 2020 und 2021 konnte Russland "taktische" wirtschaftspolitische Erfolge verbuchen. Gesamtwirtschaftlich wurde die COVID-19-Krise gut abgefedert, nicht zuletzt durch eine erstmal sehr expansive Fiskalpolitik. Zudem wurde die jüngste Verschärfung der US-Sanktionen an den Finanzmärkten gut verdaut; die "Festung Russland" war gut vorbereitet. Solche taktischen Erfolge dürfen nicht darüber hinwegtäuschen, dass wichtige Gründe für die (Einkommens-)Stagnation der letzten Jahre auch das Wirtschaftswachstum in den kommenden Jahren dämpfen werden.

\section{Geringe Komplexität, Exporte und Fiskalpolitik als Krisendämpfer}

Gesamtwirtschaftlich ist Russland gut durch das Jahr 2020 gekommen und auch zufriedenstellend ins Jahr 2021 gestartet. Mit einem Rückgang von $3 \%$ ist das Bruttoinlandsprodukt 2020 weniger stark eingebrochen als die Weltwirtschaft und nur etwa halb so stark wie in Westeuropa. Bemerkenswert ist dieses Ergebnis im Lichte einer opportunistischen Zusammenarbeit mit der OPEC im Jahr 2020. Die heimische Ölproduktion wurde im Rahmen des OPEC-plus-Abkommens gedrosselt. Die Ölproduktion fiel im Jahresvergleich um 8,5 \% im Jahr 2020, was das BIP-Wachstum um 1,0 Prozentpunkt senkte. In der Summe ist der geringe Wirtschaftseinbruch vor allem auf Wirtschaftsstrukturen, wirtschaftspolitische Reaktionen und ein besser als erwartetes globales Umfeld zurückzuführen. Die relativ geringe Komplexität der russischen Wirtschaft mit einem geringen Anteil an Dienstleistungen, die empfindlich auf Covid-19-Restriktionen reagieren, hat einen tieferen Wirtschaftseinbruch verhindert. Zudem ist Russlands Wirtschaft eher moderat international integriert; der Außenhandel liegt seit etwa einer Dekade mehr oder weniger konstant bei $50 \%$ des BIP. In Westeuropa liegt man hier eher bei $90 \%$ des BIP, in den USA oder China liegt der Außenhandelsanteil bei 20 bzw. 30 \% des BIP. Außerdem stützten die sich schnell erholenden Rohstoffexporte die Wirtschaft, während die Importe drastisch zurückgingen. Gewisse Einbußen im Öl- und Gasexport konnten durch steigende Gold und Weizenlieferungen kompensiert werden. Zudem trugen die Nettoexporte deutlich zum Zuwachs an Wirtschafsleistung bei. Da die Exporte im Jahr 2020 nur um - 5,1 \% im Jahresvergleich zurückgingen und die Importe zugleich um - 13,7 \% einbrachen, trugen die Nettoexporte mit $+1,4$ Prozentpunkten zum BIP-Wachstum bei. Für 2021 scheint sich kurzfristig eine ansehnliche Wirtschaftserholung nach der Pandemie abzuzeichnen, mit einem BIP-Wachstum um $2-3 \%$. Einige sehr zuversichtliche Prognostiker erwarten gar BIP-Wachstumsraten im Umfeld von $5 \%$ in 2021/2022, ein Szenario, das angesichts der prognostizierten Zunahme der Importe sowie der chronischen strukturellen Schwächen und Engpässe eher fraglich erscheint. Nach 2021 wird sich das Wirtschaftswachstum wahrscheinlich wieder näher am Potenzialwachstum um 1,5 bis $2 \%$ einpendeln.

Neben den skizzierten strukturellen Faktoren war vor allem eine bemerkenswerte Wende in der Fiskalpolitik erkennbar. Nach anfänglichem Zögern wurden im Jahr 2020 proaktive fiskalische Gegenmaßnahmen gesetzt, was in einem föderalen Haushaltsdefizit von 4,5\% des BIP resultierte. Zum ersten Mal reagierte die Regierung auf eine Krise, indem sie die Staatsausgaben erhöhte und vorübergehend die Fiskal-Ölpreisregel aussetzte. Zu Beginn der Krise wurde zuerst noch ein zögerliches Sozialausgabenpaket von 2,1 Billionen Rubel (knapp über 30 Milliarden Euro) bzw. knapp über $2 \%$ des BIP angekündigt. Im Juni folgte dann eine substanzielle Aufstockung der fiskalpolitischen Antwort im Rahmen des "Nationalen Plans zur wirtschaftlichen Erholung«. Mit diesem Programm will die Regierung die Wirtschaft nachhaltig unterstützen, nachdem der COVID-19-Schock abgeklungen ist. Es läuft über 18 Monate, kostet 6,4 Billionen Rubel (ca. 90 $100 \mathrm{Mrd}$. Euro) und besteht aus über 500 Einzelmaßnahmen und Programmen. Alles zusammengenommen sind damit Summen von 7 - $9 \%$ des BIP zur Krisenbewältigung mobilisiert worden. Neben Einmalzahlungen und Maßnahmen zur Einkommensstützung überschneiden sich einige der Maßnahmen im Erholungsplan mit den bereits angekündigten "Nationalen Projekten«.

Auch im internationalen Maßstab ist die fiskalpolitische COVID-19-Krisenantwort Russlands durchaus beachtlich, aber sie war alternativlos. Im Lichte der enttäuschenden Einkommensentwicklung der letzten Jahre musste sich der Kreml in dieser Krise seiner sozialpoliti- 
schen Verantwortung stellen. Das Einkommensniveau in Russland stagniert seit 2010 de facto etwa in Relation zum Einkommen in Westeuropa und beträgt (zu Kaufkraftparitäten) ca. $60 \%$ des Einkommensniveaus in der EU. Seit 2010 hat das zweitärmste EU-Land, Rumänien, zu Russlands Einkommensniveau aufgeschlossen bzw. es überholt! Eine weitere Austeritätspolitik hätte nach der Einkommenstagnation der letzten Jahre aller Voraussicht die Systemunzufriedenheit in Russland in der COVID-Krise deutlich zu Tage gebracht. Zumal die Real-Einkommensrückgänge sich auf breiter Basis vollziehen und nicht nur ärmere Bevölkerungsschichten bzw. die Bevölkerung in den Regionen betreffen. Neben der skizzierten Einkommensentwicklung im Land wäre eine Austeritätspolitik aber auch aus internationaler Perspektive der heimischen Bevölkerung kaum vermittelbar gewesen.

Interessanterweise setzt die Regierung neben sozialer Unterstützung bzw. der Stabilisierung der Einkommensentwicklung und Sicherung der Beschäftigung auch auf eine Liberalisierung und Deregulierung auf dem Arbeitsmarkt. Auch sollen kleine und mittelständische Unternehmen (KMU) von Steuererleichterungen, Zuschüssen und Subventionen profitieren. Außerdem gibt es im "Nationalen Plan zur wirtschaftlichen Erholung « einen Abschnitt zu Investitionen, digitaler Wirtschaft und Importsubstitution, der weitgehend die Ziele der Nationalen Projekte wiederholt. Große Investitionsprojekte bleiben damit ein wichtiger Teil des Konjunktur- und Entwicklungsplans. Sobald die Auswirkungen von Covid-19 abklingen, bleibt das Herzstück des Strukturreformprogramms der Regierung das ca. 25 Billionen Rubel schwere Programm der »Nationalen Projekte«, das die wichtigsten Entwicklungsziele für den Zeitraum 2019 - 2024 in den Bereichen Soziales, Wirtschaft und Umwelt umfasst. Allerdings werden die Zielsetzungen für 2024 eher erst bis 2030 als umsetzbar erachtet. Damit wird deutlich, dass das staatsgesteuerte Programm der »Nationalen Projekte« eher im Zeitverzug ist und die COVID-Krise eher als guter Anlass dient, die Implementierung zu strecken. Insofern wurde nun taktisch gegengesteuert, es wurde auf kurzfristige Ausgabenprogramme und Unterstützung auf der mikroökonomischen Ebene gesetzt, da substanzielle staatliche Infrastrukturprogramme bis dato weniger gut wirken.

\section{Taktische fiskalische Neuausrichtung, aber die »Festung-Russland «-Strategie nicht zu den Akten gelegt}

Eine gewisse fiskalische Unterstützung wird es auch in den kommenden Jahren geben - besonders auch im Jahr 2021. Der Nationale Wohlstandsfonds (NWF) wird aufgrund vorübergehender Änderungen der Fiskalregeln nicht wieder aufgefüllt; eine Wiederauffüllung könnte frühestens im Jahr 2022 wieder aufgenommen werden. Die liquiden Mittel des NWF sollen mit dem Fokus auf Infrastrukturprojekte investiert werden, da ihre Summe den Schwellenwert von 7 \% des BIP überschreiten. Daher werden weiterhin politisch gewollte Wachstumsimpulse gesetzt. Das ist eine Änderung im Vergleich zur Vorkrisen-Stagnationsphase. Zudem wurden mit dem zuvor skizzierten Aufbauplan im Kontext des Wahlkalenders 2021 Erhöhungen der Sozialausgaben und Einmalzahlungen angesetzt. Allerdings betonte der russische Finanzminister jedoch umgehend, dass diese Unterstützungsmaßnahmen keine zusätzliche und substanzielle Schuldenemission und Finanzierung erfordern. Insofern wird auch hier deutlich, dass man die mögliche Limitation durch internationale Sanktionen nicht ausreizen will. Langfristig ist keine weitere Erhöhung der Staatsschuldenquote zu erwarten.

Hier ist zu betonen, dass die lange erwartete Verschärfung der internationalen Sanktionen gegen Russland in den letzten Wochen, insbesondere die US-Finanzsanktionen, gut verkraftet wurden. Die Auswirkungen auf die Finanzmärkte und den Rubel blieben überschaubar, was mit der »Festung-Russland «-Strategie, die seit 2014 verfolgt wird, zu tun hat. Man hat sich auf eine Verschärfung der Sanktionen in vielen Dimensionen vorbereitet. Die Auslandsschulden wurden getilgt, die Devisenreserven sind weiter gestiegen und übersteigen die Auslandsschulden in absoluten Zahlen. Die Positionen westlicher ausländischer Banken gegenüber Russland stagnieren seit Jahren, was Kapitalflussrisiken ebenfalls reduziert. In begrenztem Ausmaß hat der russische Staat in den letzten Jahren und auch zuletzt noch Geld an den internationalen Finanzmärkten aufgenommen, aber dies dann in Euro und nicht US-Dollar. Alles in allem ist Russland damit weniger abhängig vom internationalen Finanzmarkt und in gewissem Maße auch vom US-Dollar und internationalen Zahlungsstrukturen. Zudem neigt die Russische Zentralbank im Zweifel eher zu einer restriktiven Geldpolitik, um Abwärtsrisiken für den Rubel zu begrenzen. Außerdem ist der russische Bankensektor nach der Restrukturierung der letzten Jahre in einer soliden Verfassung. Staatsanleihen machen nur $7 \%$ der Gesamtaktiva aus, verglichen mit $15-20 \%$ in anderen Märkten. Daher könnten die lokalen Banken die sanktionierten Staatsanleihen gut absorbieren - falls nötig.

Vor der jüngsten Sanktionsverschärfung hatten sich am Finanzmarkt die Spekulationen etwas verselbständigt, teils auch unter internationalen Investoren. Insofern handelte der Rubel zeitweise $10-15 \%$ unter seinem Niveau, was an sich durch Fundamentaldaten gerechtfertigt wäre. Angesichts dieser »Sanktionsblase« erholte sich der Rubel nach der Sanktionsrunde im April sogar erkennbar. 


\section{Ausblick auf die Sanktionspolitik: Auf Dauer ausgelegt, in Zukunft mehr}

Die jüngste Verschärfung der Sanktionen durch die USA war gut telegrafiert. Am wichtigsten für die Finanzmärkte ist, dass die Maßnahmen zwar den Kauf von Rubel-denominierten Staatsanleihen auf dem Primärmärkt (also direkt vom Staat) verbieten, aber dies "nur« für US-Finanzinstitute. Zuvor war es (seit 2019) für US-Banken sanktioniert, Russlands Staatsanleihen in Fremdwährung auf dem Primärmarkt zu kaufen. Allerdings hat dies den internationalen Handel dieser Wertpapiere am Sekundärmarkt (also von Investoren untereinander) nicht drastisch beeinflusst. Die nun vollzogene vollständige Sanktionierung von allen russischen Staatsanleihen für US-Banken auf dem Primärmarkt ist ein starkes politisches Signal, die praktische Relevanz ist begrenzt. Die lokalen Staatsbanken haben genügend Kapazität, die Emission von Staatsanleihen zu absorbieren. Und solange die sanktionierten Wertpapiere von US-Banken an den Sekundärmärkten gehandelt werden können, sind die Sanktionsauswirkungen begrenzt. Außerdem sind die Sanktionsmaßnahmen im Bereich der Staatsanleihen auf US-Finanzinstitute beschränkt, was die Auswirkungen auf US-Investoren (also NichtBanken wie Pensionsfonds etc.) oder auch Nicht-USBanken in Summe geringhält. Bislang wird hier keine Extraterritorialität angestrebt. Insofern ist es nicht überraschend, dass auch die Russische Zentralbank, trotz harscher diplomatischer Reaktionen auf die US-Finanzmarktsanktionen, klar Stellung bezog. Die Gouverneurin der Russischen Zentralbank Elvira Nabiullina brachte die geringe unmittelbare Auswirkung der Verschärfung der Sanktionen auf die Realwirtschaft und die Finanzmärkte klar zu Sprache - auch wenn die Notenbank wegen der Sanktionen eine vorsichtige Zinspolitik verfolgt.

Bislang haben die USA von weitreichenden Maßnahmen, wie z. B. dem Verbot des Sekundärmarkthandels oder dem Ausschluss russischer Unternehmen aus dem internationalen SWIFT-Zahlungssystem oder von US-Dollar-Zahlungen, abgesehen. Schon die Primärmarktsanktionen als Teil des jüngsten Sanktionspakets waren sogar etwas überraschend. Dieser Schritt war vor allem mit der Dringlichkeit begründet, ein klares Signal nach der geopolitischen Eskalation, ausgelöst durch Russlands groß angelegte Manöver an der Grenze zur Ukraine, zu senden. Allerdings ist das Risiko einer Ausweitung der Sanktionen bei Staatsanleihen damit nun gestiegen, da dies dann der nächste weitere Schritt ist. Auch wenn die US-Sanktionen bisher moderat waren, ist eine weitere, graduelle und erkennbare Verschärfung im Sinne der zuvor skizzierten Optionen nicht auszuschließen. Aus US-Perspektive sind die derzeitigen maßvollen Sanktionen, kombiniert mit dem Bemühen im Dialog zu bleiben, darauf ausgerichtet eine Eskalation zu vermeiden. Es sieht jedoch nicht so aus, als ob dieser Ansatz in Russland gut verstanden wird. Hinzu kommt, dass es in den USA erheblichen politischen Druck in Richtung einer stärkeren Sanktionierung gibt. Die jüngsten Schritte werden nur als "erster Schritt" in die richtige Richtung gesehen; einige Beobachter stellen klar, dass die Sanktionen offenbar zu leicht waren. Zudem sollte nicht vergessen werden, dass Sanktionen gegen Russland auf den internationalen Märkten durch die USA ein (indirektes) politisches Signal in Richtung China sind.

Insgesamt bleibt das Risiko für weitere westliche und vor allem US-Sanktionen hoch, es besteht keine Aussicht auf eine Lockerung. Wir befinden uns derzeit im siebten Jahr der umfassenden westlichen Finanzsanktionen gegen Russland, mit Verschärfungen vor allem in den Jahren 2019 und 2021. Die Empirie von "erfolgreichen" westlichen Sanktionsregimen, d. h. solchen, bei denen eine Verhaltensänderung der sanktionierten Partei erkennbar war, deutet auf eine Dauer von sieben bis zehn Jahren hin. Ansonsten dauern Sanktionen meist viel länger, manchmal über Jahrzehnte an. Im Falle Russlands ist zu erwarten, dass die westlichen Sanktionen mindestens bis weit in die 2020er Jahre, möglicherweise bis in die 2030er Jahre bestehen werden. Dieses Szenario impliziert, dass es mehr Risiken für eine ad-hoc und moderate Eskalation gibt als Möglichkeiten zur Deeskalation. Daher wird die wirtschaftspolitische »Festung-Russland «-Strategie wahrscheinlich fortgesetzt werden, obwohl sie für Wachstum und Wohlstand nicht förderlich ist. Hinzu kommt, dass in Russland ein bekanntes "Sanktionsparadoxon" am Werk zu sein scheint: Die Regierung, das Militär und der Sicherheitsapparat werden gestärkt, da diese Kreise den Sanktionen besser standhalten können als private Unternehmen. Damit dominieren dann aber auch Bestandswahrungsinteressen die Wirtschaftspolitik; der Appetit auf umfassende Strukturreformen ist gering.

Wir sehen begründet durch zahlreiche Faktoren erstmal ein teil-stabiles Gleichgewicht in den amerikanischrussischen Beziehungen voraus. Derzeit sehen wir ein ausdrückliches Bekenntnis zu Rüstungskontrollgesprächen; der Kreml bleibt offen für eine Zusammenarbeit auf diesem Gebiet. Hier hat der Kreml erreicht, was er will: Die USA sprechen mit Russland auf Augenhöhe. Solange Russland seine geopolitischen Karten gut ausspielt und der Kreml seinen makrofinanziellen Spielraum richtig einschätzt - wie er es normalerweise tut erwarten wir nicht, dass die USA komplett erdrückende Sanktionen verhängen werden. Aber wohldosierte geopolitische Provokationen oder Überraschungen sowie harte Maßnahmen zur Eindämmung der Opposition sind aber immer möglich, und damit weitere gesichtswahrende, aber eher kosmetische westliche Sanktionen. 
Für solche Szenarien ist Russland aber gut vorbereitet und kann zugleich die chronische Wachstumsschwäche auf das westliche Sanktionsumfeld schieben.

\section{Taktische Fiskalpolitik ändert nichts am Stagnationsausblick}

Wie skizziert konnte Russland einige kurzfristige "taktische« wirtschaftspolitische Erfolge verbuchen. Vor allem wurde die Fiskalpolitik kurzfristig deutlich expansiver gestaltet. Dies sollte jedoch nicht von den schwierigen mittelfristigen Aussichten ablenken. Die staatszentrierte, international zunehmend wenig integrierte und sanktionierte russische Wirtschaft stagniert de facto seit Jahren, bisherige staatliche Investitionsprogramme haben keine wachstumsfördernde Wirkung entfaltet. Substanzielle Strukturreformen sind mit dem "Nationalen Plan zur wirtschaftlichen Erholung« nicht verbunden, auch wenn hier nicht nur auf Großunternehmen und staatliche Investitionsprogramme gesetzt wird. Die Realeinkommen stagnieren oder sinken seit 2014, auch wenn 2021 eine leichte Trendwende eintreten könnte. Allerdings gibt es auch schon wieder Risiken für dieses Szenario. Aktuell sehen wir einen deutlichen Anstieg der (Lebensmittel-)Inflation. Nun muss die Zentralbank schon wieder Gegenmaßnahmen ergreifen, um den Inflationsdruck zu begrenzen und den Rubel weiter abzusichern. Letzteres ist auch Teil der »Festung-Russland «-Strategie, die in der Summe kein wachstumsfreundliches Umfeld bedeutet. Die »Festung-Russland«-Strategie schafft auch nicht unbedingt Vertrauen bei ausländischen Wirtschaftsakteuren. Vielmehr ist eine Stagnation des ausländischen Engagements in der russischen Wirtschaft zu beobachten, während sich die russischen Lieferketten zunehmend nach innen richten.

\section{Über den Autor}

Gunter Deuber ist Chefökonom bei der auf Osteuropa und Russland spezialisierten »Raiffeisen Bank International AG« (RBI AG) in Wien, eine der größten Auslandsbanken in Russland. Gunter Deuber wurde 2019 für das IVLP-Programm (International Visitor Leadership Program) des US-Außenministeriums nominiert und hatte die Möglichkeit, politische Entscheidungsträger und Regulierungsbehörden in den USA persönlich zu treffen. Der vorliegende Beitrag gibt die persönliche Auffassung des Autors und nicht notwendigerweise die Ansicht der RBI AG wieder.

\section{Russlands Wirtschaft - Covid-19, Entwicklung und Prognosen}

\section{Grafik 1: Reales BIP-Wachstum und Prognosen (\% gegenüber Vorjahr)}

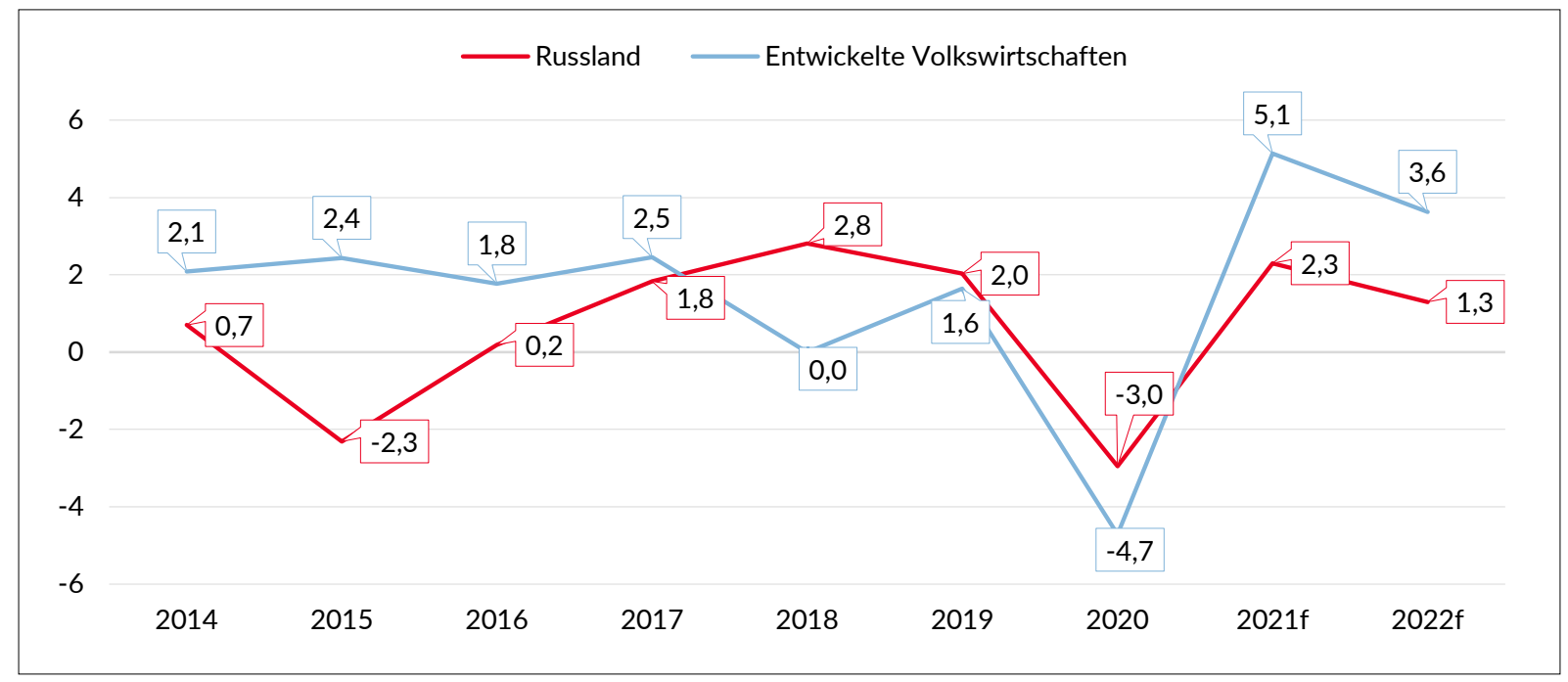

$f$ - Die Werte für die Jahre 2021 und 2022 sind Vorhersagewerte.

Quelle: nationale Statistiken, Internationaler Währungsfonds, RBI/Raiffeisen Research 
Grafik 2: Wirtschaftswachstum Post-COVID und langfristig (\% gegenüber Vorjahr)

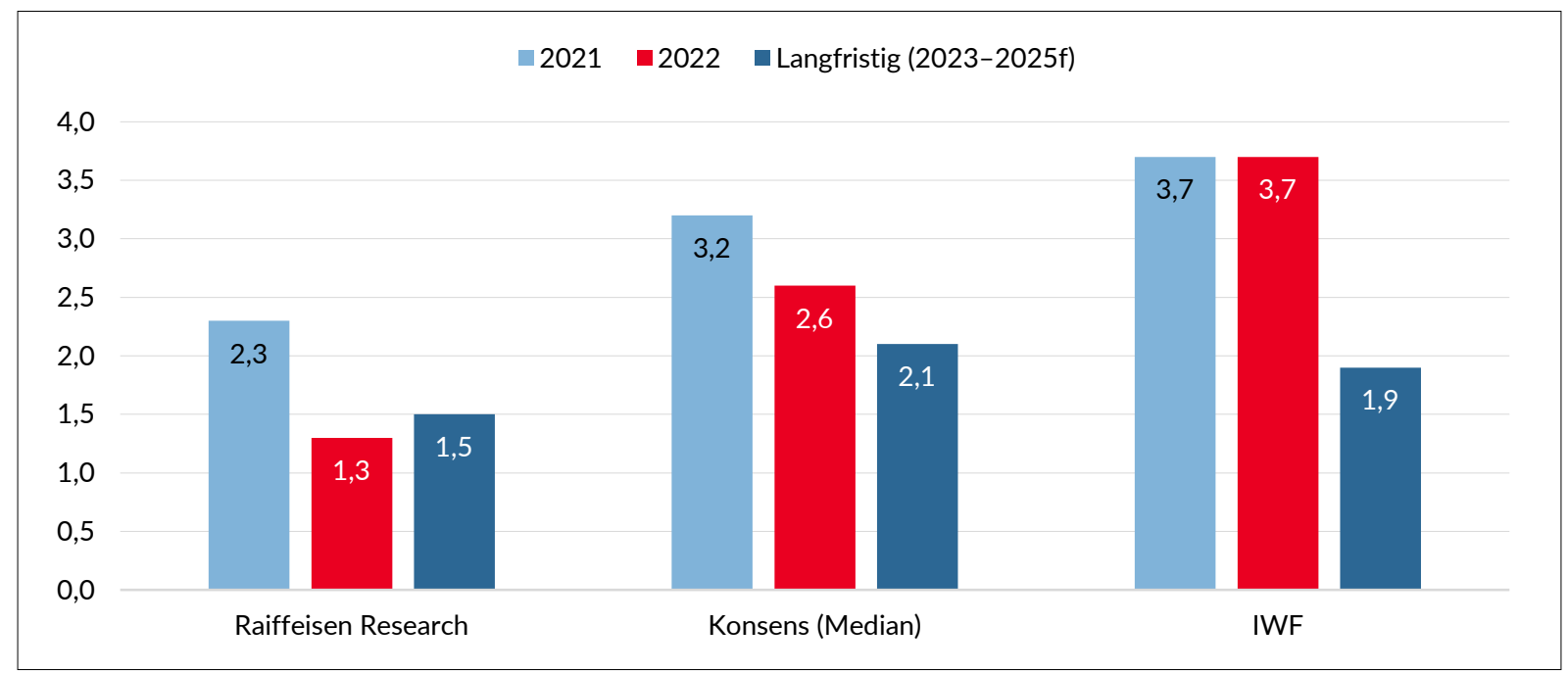

$f$ - Die Werte für die Jahre 2023 bis 2025 sind Vorhersagewerte. Quelle: IWF, FocusEconomics, RBI/Raiffeisen Research

\section{Grafik 3: COVID-19-Wirtschaftskrise im Vergleich zu früheren Wirtschaftskrisen}

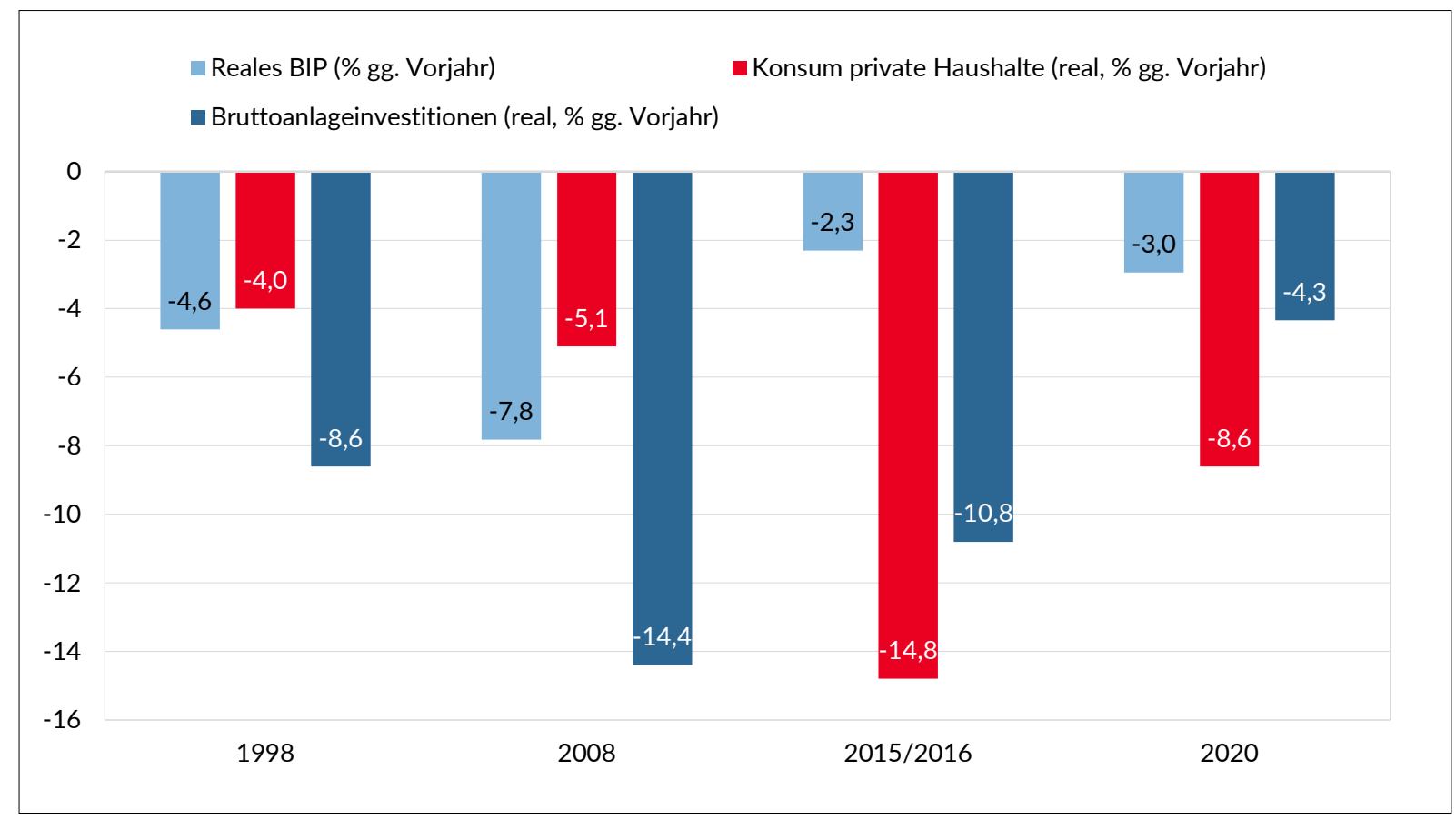

Quelle: nationale Statistiken, RBI/Raiffeisen Research 
Grafik 4: Pro-Kopf-BIP (zu Kaufkraftparitäten, \% des EU-Durchschnitts)

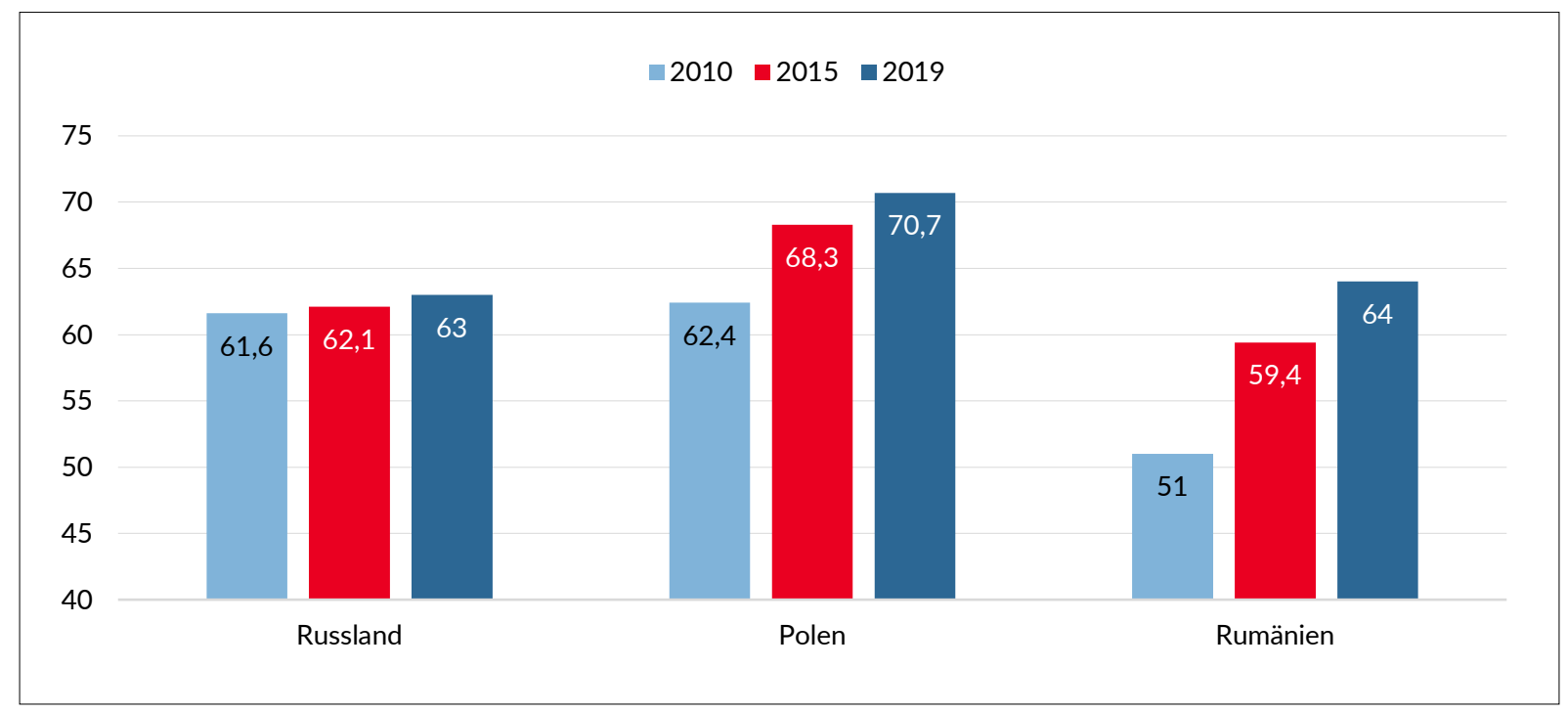

Quelle: nationale Statistiken, Internationaler Währungsfonds, Eurostat, RBI/Raiffeisen Research

\section{Grafik 5: Nominaler Monatslohn (in EUR)}

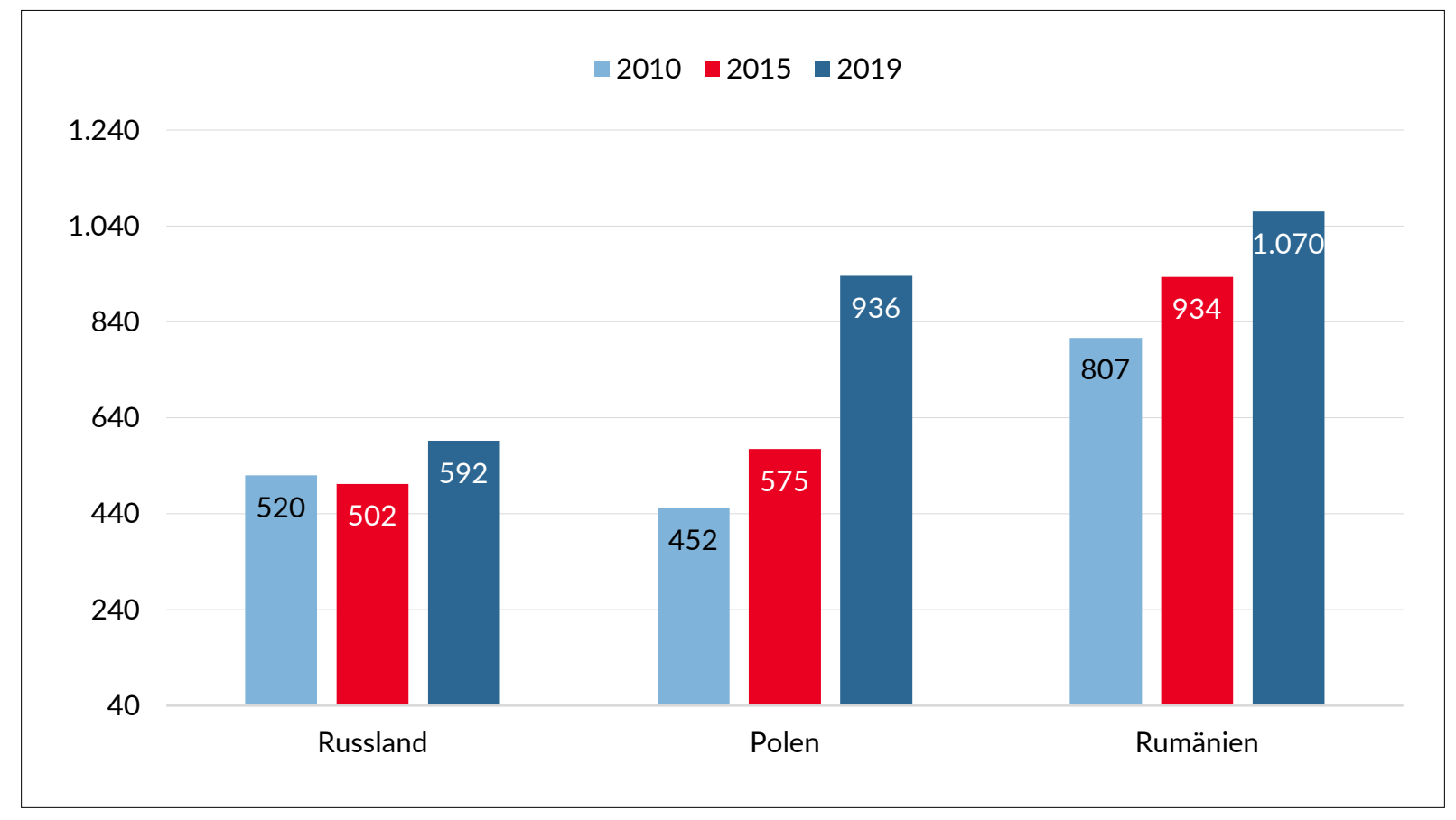

Quelle: nationale Statistiken, Internationaler Währungsfonds, Eurostat, RBI/Raiffeisen Research 
Grafik 6: Anteil ausländischer (nicht-gebietsansässiger) Halter für Lokalwährungsstaatsanleihen (OFZ) am russischen Markt

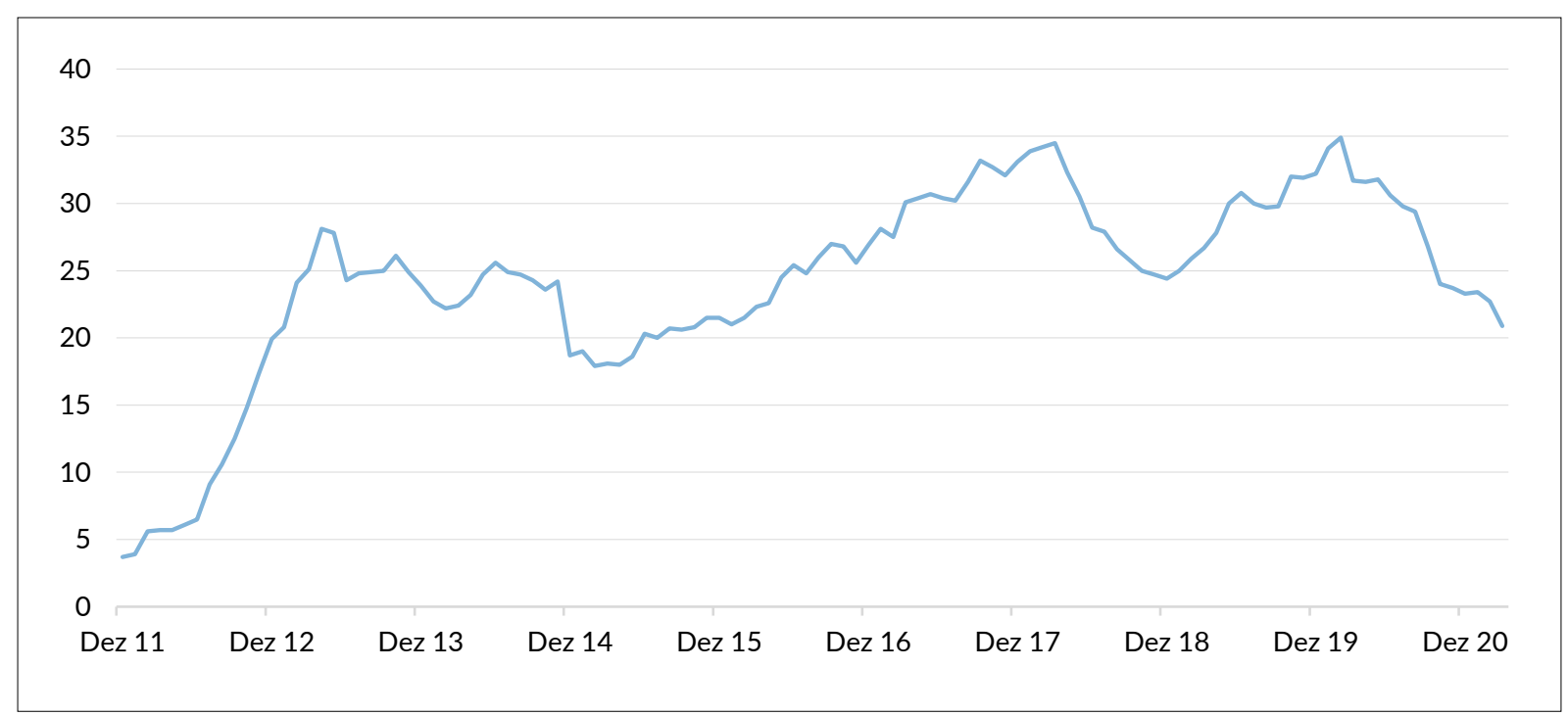

Quelle: Russische Zentralbank, RBI/Raiffeisen Research

\section{Grafik 7: Entschuldung und Devisenreservenaufbau}

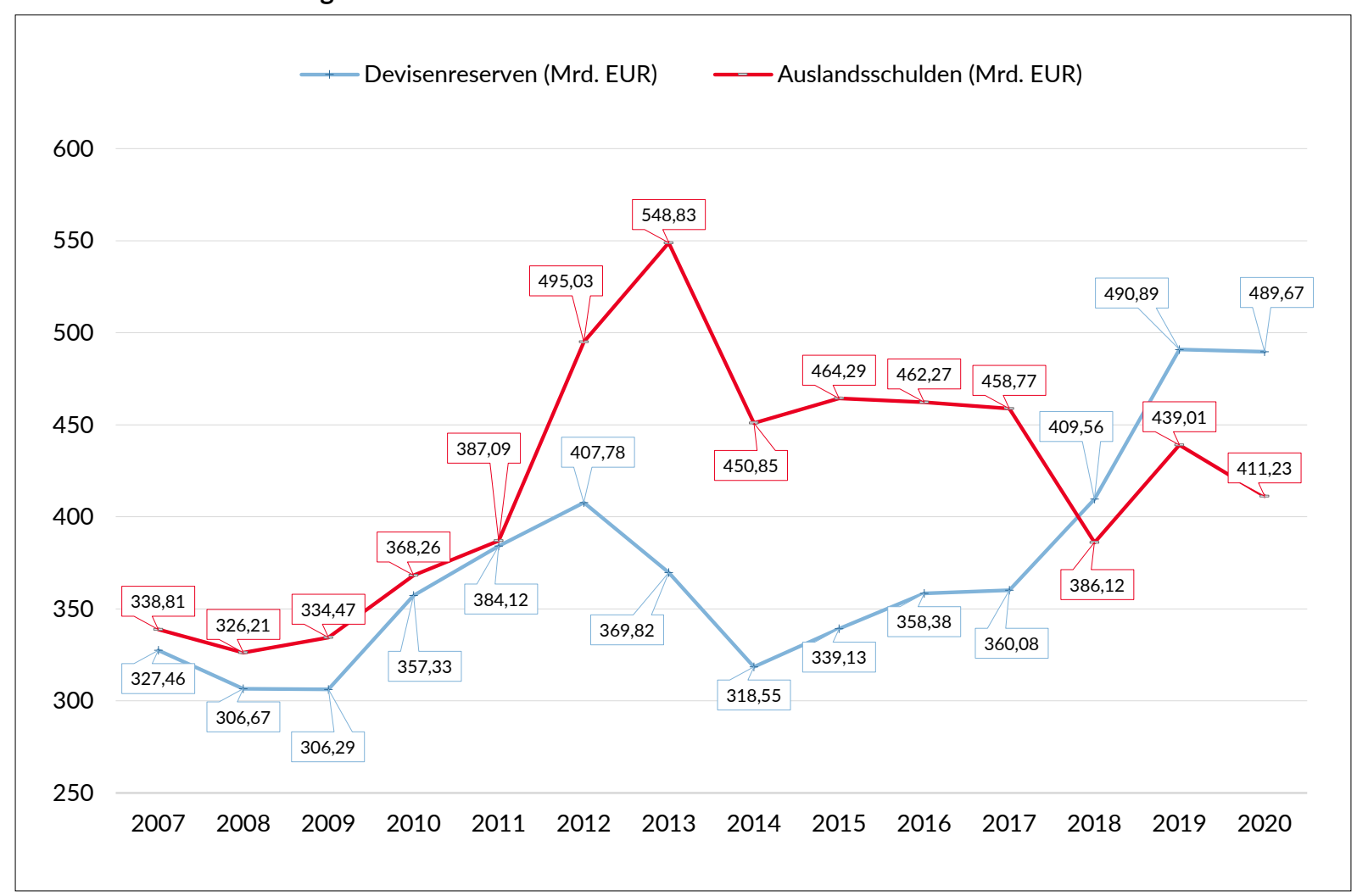

Quelle: nationale Statistiken, Russische Notenbank, RBI/Raiffeisen Research 
Grafik 8: Forderungen ausländischer (westlicher) Banken gegenüber Russland (Milliarden USD)

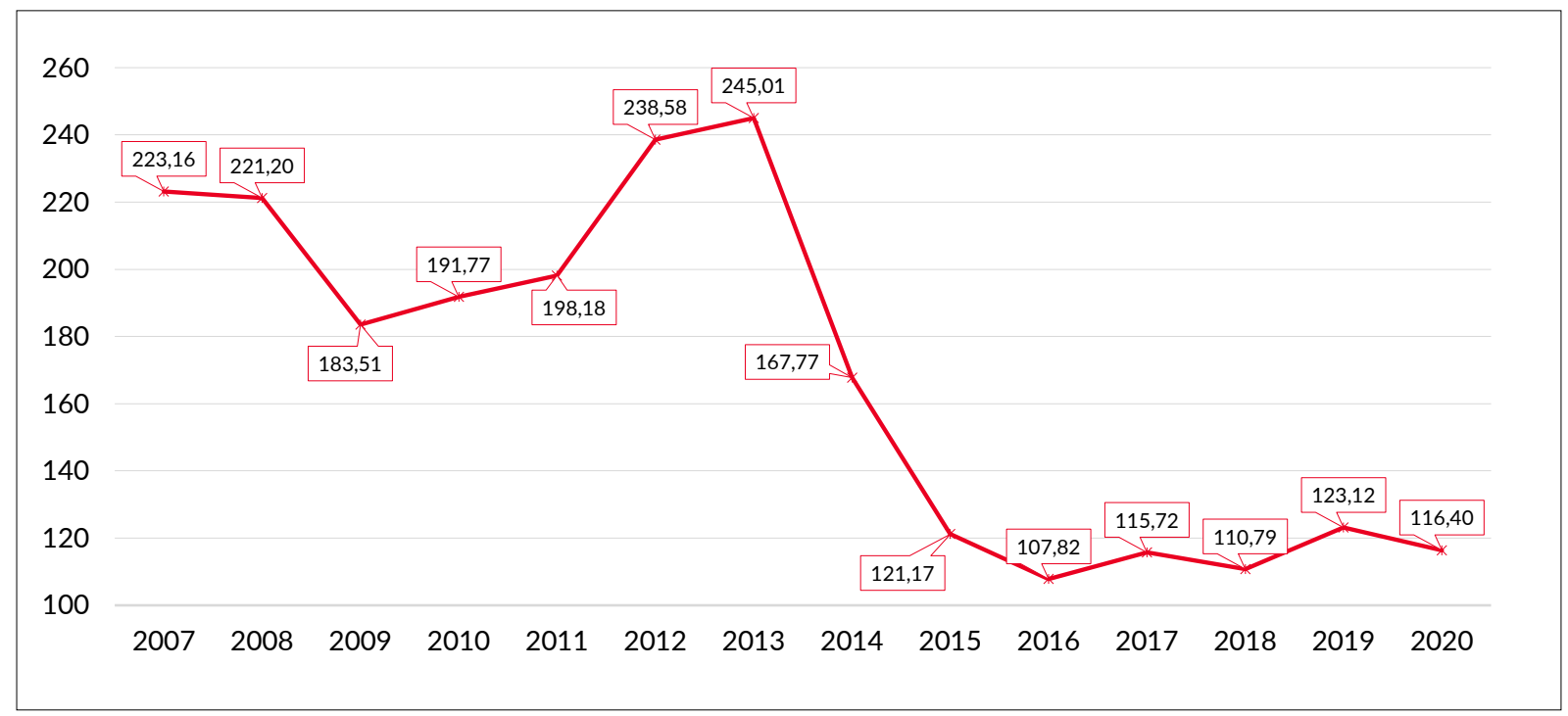

Quelle: Bank für Internationalen Zahlungsausgleich, RBI/Raiffeisen Research

\section{Grafik 9: RUB/USD Wechselkurs (Periodenende)}

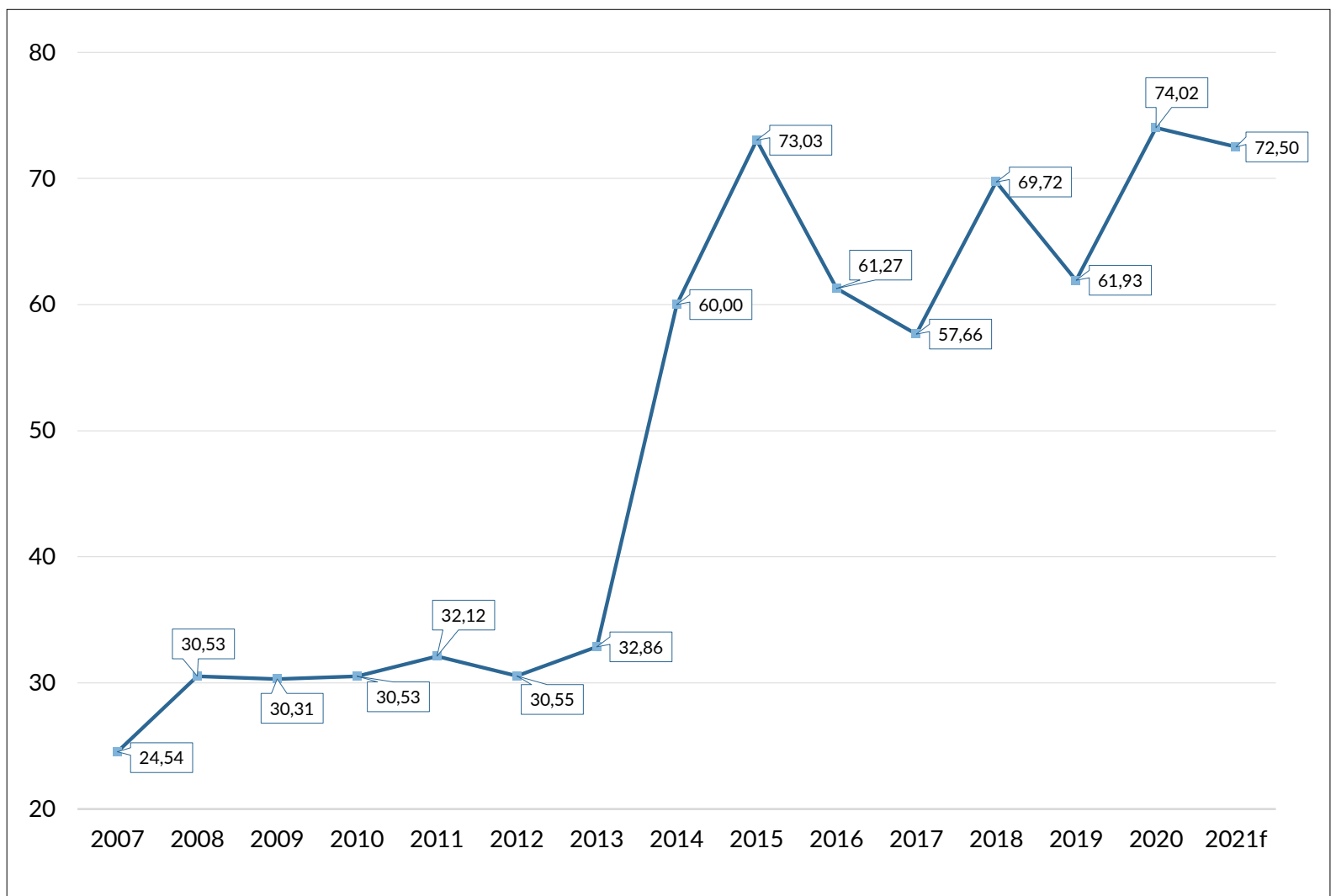

$f$ - Der Wert für das Jahr 2021 ist ein Vorhersagewert. Quelle: Russische Notenbank, RBI/Raiffeisen Research 


\title{
Russische kleine und mittlere Unternehmen (KMUs) in der Corona-Krise - Ein Sterben auf Raten
}

\author{
Michael Martin Richter (Forschungsstelle Osteuropa an der Universität Bremen)
}

DOI: $10.31205 /$ RA.404.02

\section{Zusammenfassung}

Seit vielen Jahren verspricht die Elite Russlands die Stärkung der kleineren und mittleren Unternehmen (KMUs) und deren Rolle in der Volkswirtschaft. Manchmal überschlägt sich dabei die politische Rhetorik im Eifer des Gefechts und zuvor ausgerufene Ziele müssen revidiert werden. So geschehen auch mit den mittelfristigen Entwicklungszielen der KMUs, das heißt Firmen mit bis zu 250 Beschäftigten und 2 Mrd. Rubel Umsatz (ca. 30 Mio. Euro). Diese wurden im Nationalen Projekt mit dem Titel »kleine und mittlere Unternehmen und die Förderung des individuellen Unternehmertums « festgehalten. Zuerst sollte der Anteil dieser Unternehmen am BIP bis zum Jahr 2030 auf $40 \%$ steigen, was später auf 32,5 \% gesenkt wurde. Damit wäre das Land jedoch immer noch deutlich hinter anderen Industrienationen. In der EU beispielsweise betrug der Anteil 2019 knapp 56 \%. Im Vergleich dazu steuerten russische KMUs im gleichen Zeitraum nur knapp $20 \%$ zum BIP bei und selbst dieser niedrige Wert war seit einigen Jahren rückläufig. Die Probleme dafür sind im polit-ökonomischen System selbst zu finden und geben zudem Aufschluss darüber, wie und weshalb die politischen Lenker im Kreml auf die Corona-Krise antworteten und welche Konsequenzen dieses Handeln langfristig haben kann.

\section{Die Auswirkungen des politischen Systems in Russland auf KMUs}

Die wirtschaftlichen Strukturen des Landes ähneln stark den politischen. Dies ist auf die Politisierung der Wirtschaft zurückzuführen, die eine Konsequenz des Regimetyps ist. Im Klartext handelt es sich beim flächenmäßig größten Land der Erde um einen autoritären Staat. Davon können zwei wichtige Einsichten in Bezug auf den Stellungswert von KMUs in einem solchen politischen System abgeleitet werden:

Erstens werden KMUs von den Machthabern höchstens als schlechtere Alternative zu Großunternehmen gesehen. Das liegt vor allem daran, dass Letztere, insbesondere wenn es sich um staatseigene Unternehmen handelt, einfacher zu kontrollieren sind, bzw. direkt für politische und finanzielle Interessen des Kremls eingesetzt werden können. Somit sind z. B. mehr oder minder verpflichtende Wahlkampagnen in Großunternehmen ein häufiges Instrument, um die Wahlbeteiligung zu erhöhen. Gleichzeitig kann der potenzielle Verlust seines Arbeitsplatzes in einem Unternehmen für Arbeitnehmer abschreckend im Hinblick auf politischen Aktivismus wirken. Je höher somit der Beschäftigtenanteil in Großunternehmen ist, umso einfacher kann von diesen Instrumenten Gebrauch gemacht werden; was in KMUs unter gleicher Zielsetzung aus rein logistischen Gesichtspunkten weniger praktikabel wäre. Entsprechend dieser Devise gehen Berechnungen davon aus, dass ungefähr jeder zweite formell beschäftigte Arbeitnehmer in Russland in einem Unternehmen mit Staatsbeteiligung angestellt ist. Gleichzeitig können auch Entscheidungen von wenigen, bedeutenden Großunternehmen einfacher politisch gesteuert werden. Sie können so z. B. für außenpolitische Zwecke, wie im Falle von Gazprom, oder Patenschaften für Prestigeprojekte auf lokaler, regionaler als auch auf föderaler Ebene genutzt werden. Es ist somit nicht verwunderlich, dass der Übergang in ein autokratisches System in Russland, der insbesondere nach der Machtübernahme Putins an Tempo zulegte, Hand in Hand mit der Zentralisierung sowie Verstaatlichung von zentralen Wirtschaftszweigen einherging.

Zweitens sind es die Auswüchse einer Autokratie, die stellvertretend für die Probleme stehen, die KMUs heute in Russland daran hindern, zu wachsen. Die politische Vereinnahmung von Großunternehmen in einem System mit formell schwachen Institutionen führte zu einer Zentralisierung der Korruption. Diese ging mit der Instrumentalisierung der Justiz einher, welche ein Mittel zum Zweck in den Händen des Kremls und ihm nahestehender Personen darstellt. Das daraus resultierende unsichere institutionelle Umfeld und die Gefahr von Enteignungen stellt eine ungemeine Barriere für privates Unternehmertum dar. Wettbewerb zwischen Unternehmen findet in einem solchen System weniger auf der Basis von wirtschaftlichen Aspekten denn des Zugangs zu politischen Ressourcen statt. So ist es wenig verwunderlich, dass es dann gerade die Großunternehmen sind, die im wirtschaftlichen Wettbewerb die mit Abstand besten Karten haben. Diese Wettbewerbsverzerrung ist insbesondere wichtig im Hinblick auf den Unterschied zwischen den theoretischen und den faktischen Rahmenbedingungen zum Führen eines Unternehmens. 
Aus der politischen Lenkung des freien Wettbewerbs auf dem Markt speist sich die generelle Einstellung von autoritären Staaten gegenüber internationaler Kooperation. In der Wissenschaft allseits bekannt ist die Theorie des demokratischen Friedens, die besagt, dass demokratische Staaten deutlich weniger Kriege gegeneinander führen. Gleichweg findet auch die These breite Zustimmung, dass diese Staaten stärkeren Handel mit der Außenwelt betreiben. Russland ist keine Ausnahme dieser Regel, sondern ein gutes Beispiel im umgekehrten Sinne. Mit zunehmendem Autoritarismus nahmen auch die Konflikte mit Nachbarländern zu, die wirtschaftlich in den Sanktionen, Embargos und der zunehmenden Isolierung Russlands kulminierten. Dies geschah parallel zu einer breit angelegten Strategie der Importsubstitution, bei der ausländische Güter durch einheimische Produkte ersetzt werden sollten. Insbesondere protektionistische Maßnahmen wurden dafür eingesetzt, die jedoch bei Ausbleiben von systemischen Reformen eine Umverteilung von breiten Bevölkerungsschichten zu Gunsten einiger, wenig konkurrenzfähiger Wirtschaftszweige darstellen.

Diese Einschränkungen sind von zentraler Bedeutung. Denn das seit längerem rückläufige Kaufkraftniveau in Russland ist eine buchstäbliche Folge dieser Entwicklungen. Selbst wenn KMUs von keinen direkten Folgen des unsicheren institutionellen Umfelds getroffen werden sollten, beispielsweise in Form von Enteignungen, so sind sie dennoch durch diese wirtschaftliche Stagnation gebeutelt. Im Unternehmensbarometer der KMU-nahen Organisation »Opora« wurde bereits lange vor der Corona-Krise das Fehlen an heimischer Produktnachfrage als Hauptgrund für eine negative Wirtschaftslage der KMUs erkannt. Diese Not wird dadurch erhöht, dass Russlands KMUs in überwältigender Mehrheit ausschließlich auf dem heimischen Markt agieren und nur für knapp $9 \%$ der russischen Ausfuhren außerhalb des Rohstoffsektors stehen. Dies erklärt auch, wieso bereits vor dem Ausbruch der Covid-19-Pandemie der Anteil russischer KMUs an der Wirtschaftsleistung des Landes zurückging, da jene überproportional von den hausgemachten Nachfrageproblemen getroffen waren.

\section{Wieso der Staat 2020 anders als 2009 handelte}

Die Pandemie traf somit auf einen bereits angeschlagenen und im besten Falle stagnierenden KMU-Sektor in Russland. Der zuvor genannte Zugang zu politischen Ressourcen als wichtigstes Mittel zur Wettbewerbsführung wird dabei auch deutlich in den Anpassungsmechanismen an Krisen sichtbar. Es gab zwar Stützungsmaßnahmen, die die russische Regierung den durch die Corona-Krise gebeutelten Unternehmen anbot. Jedoch war die Dimension dieser Maßnahmen eine völ- lig andere im Vergleich zu anderen, insbesondere westlichen Ländern. Gerade einmal 4,5 \% des BIPs veranschlagten all diese Maßnahmen bis Mai 2021. Im Vergleich dazu fielen die Stimuli und Hilfen in den USA mit $26 \%$ und Deutschland mit $39 \%$ des BIPs um ein Vielfaches höher aus. Auch waren direkte Unterstützungszahlungen, die man in Deutschland u. a. als Überbrückungshilfen kennt, kaum Bestandteil der Maßnahmen der russischen Regierung. Ein Finanztopf zur Stützung von KMUs wurde zwar aufgelegt, jedoch enthielt er gerade einmal $80 \mathrm{Mrd}$. Rubel, was in etwa 1 Mrd. Euro entspricht. Während der ersten Welle, als sich das Land im Lockdown befand, wurden 12.000 Rubel pro Arbeitnehmer an Unternehmen ausgezahlt. Dies geschah unter der Bedingung, dass die Firma mindestens 90 \% der Arbeitsplätze der Vorkrisenzeit beibehielt. Dass dies jedoch mit umgerechnet 170 Euro pro Kopf eine ziemlich bescheidene Hilfszahlung ist, muss hierbei nicht gesondert erwähnt werden. Einen direkten Kanal, um Umsatzausfälle zu kompensieren, ähnlich der in Deutschland bekannten Maßnahmen, gab es in Russland so gesehen nicht.

Wie Umfragen zeigen, nahmen KMUs neben dem Zurückgreifen auf Eigenmittel in erster Linie Kredite auf, um mit den negativen Konsequenzen der Pandemie zurechtzukommen. Von Seiten der Regierung wurden dafür die Voraussetzungen zur Kreditvergabe gelockert und Staatsbanken spielten eine beträchtliche Rolle in der praktischen Umsetzung. Ein spezielles Programm wurde explizit für KMUs aufgesetzt, das vorsah, kurzfristige Kredite (bis zu 12 Monate) mit einer niedrigen Verzinsung zur Verfügung zu stellen. In der Praxis stellte sich jedoch heraus, dass diese Kredite häufig verwehrt wurden und eine hohe Ablehnungsquote (bis zu $70 \%$ in der ersten Welle) ließ sogar den WirtschaftsOmbudsmann, Boris Titov, im Kreml intervenieren, was letztlich von Erfolg geprägt war. Die gelockerten Bedingungen zur Kreditvergabe wurden von Seiten des Staates durch ein Moratorium für Inspektionen und einer Lockerung der Insolvenzregelungen komplementiert. Hinzu kamen Stundungen bzw. Verlagerungen für die Zahlung von Steuerschulden sowie Sozialabgaben. In der Gesamtwirtschaft sollen diese Maßnahmen zu Einsparungen von rund $25 \mathrm{Mrd}$. Euro (ca. 2 Billionen Rubel) geführt haben. Jedoch waren sie, wie bereits erwähnt, relativ bescheiden in ihrem Umfang, insbesondere in Anbetracht der knapp 118 Milliarden Euro, die der staatliche »Nationale Vermögensfonds" Russlands, der für genau solche Krisen gedacht ist, im März 2020 zur Verfügung hatte. Diese Tatsache wirkt noch paradoxer, wenn gleichzeitig die weitere Wertentwicklung dieses Vermögensfonds betrachtet wird. Der Gesamtwert stieg nämlich bis August 2020 auf über $145 \mathrm{Mrd}$. Euro an, da der Goldpreis im Zuge der Pandemie anzog 
und das Edelmetall inzwischen die Größte Position dieses Fonds darstellt.

Dass der russische Staat jedoch auch anders wirtschaften kann, wurde während der Weltwirtschaftskrise 2009 sichtbar. Damals pumpte der Kreml den Gegenwert von 6,8 \% seines BIPs in den Markt in Form von Stützungsmaßnahmen und Stimuli, was den größten Wert aller G20-Staaten darstellte. Knapp $45 \%$ des damaligen Reservefonds, der 2018 mit dem Nationalen Vermögensfond fusionierte, wurden dafür aufgebraucht. Dabei zeigten Studien, dass von diesen enormen Summen überproportional stark Großunternehmen profitierten. Dies trifft auch im Kern einen der zwei Gründe, weshalb der Kreml im Vergleich zu 2009 in der CoronaKrise einen Paradigmenwechsel vollzog und deutlich zurückhaltender agierte.

Erstens kann anhand von Unternehmensdaten abgelesen werden, dass in erster Linie KMUs von den Einschränkungen der ersten Welle getroffen waren. Während angenommen wurde, dass die Gewinne der größten Unternehmen des Landes um 8 \% fallen werden, fielen sie für die anderen Unternehmen um rund $40 \%$. Zweitens wird der 2009 noch nicht in diesem Ausmaß vorhandene Fiskalkonservatismus des Kremls als zusätzlicher Grund für das Ausbleiben einer größeren Reaktion 2020 sein. Es wurde viel über die russische Strategie der relativen Unabhängigkeit von globalen Schocks, ergo auch Sanktionen, geschrieben. Die Idee einen großen fiskalischen Puffer zu haben, um so den Einfluss von heutigen und potenziell zukünftigen Strafmaßnahmen zu verringern, scheint den Kreml spätestens seit der Ukrainekrise prioritär umzutreiben. Dies führte dazu, dass der Fiskalkonservatismus und die gleichzeitige Strategie zur Importsubstitution an Fahrt aufnahmen.

\section{Staatliche Hilfen - nicht nur ein Angebotsproblem}

Bei einer genaueren Untersuchung der KMUs wird dabei jedoch sichtbar, dass nicht einzig und allein das wenig ambitionierte Hilfspaket der russischen Regierung von Bedeutung ist. Selbst dieses eher bescheidene Angebot traf auf eine geringe Nachfrage seitens der Unternehmen. Die Betrachtung der Gründe für diesen Zustand führt wiederum zu den eingangs erörterten politischen Merkmalen des Systems Putin. Laut Experten der Hochschule "RANEPA« nahmen knapp 90 \% der KMUs die eigentlich verfügbaren Hilfen nicht an. Als Hauptgrund wurden das mangelnde Vertrauen der Unternehmer in die russische Regierung, die niedrigen Unterstützungssummen, sowie übermäßige Bürokratie angeführt. Andere Studien kamen zum Ergebnis, dass zwar $40 \%$ der KMUs irgendeine Art von Hilfe in Anspruch nahmen, was dennoch $60 \%$ der Unternehmen außen vorlässt.
Diese Kombination an mangelnder Nachfrage und eines mangelnden Angebots an staatlicher Unterstützung kann sich jedoch als tickende Zeitbombe herausstellen. Denn dadurch, dass in erster Linie Stützungskredite aufgenommen wurden, ist ein deutlicher Anstieg der Schuldenlast zu beobachten. Knapp zwei Drittel der kleinen Unternehmen in Russland werden inzwischen als Schuldner gesehen. Da die Kredite in der Regel für einen kurzen Zeitraum gedacht waren, nahen Rückzahlungstermine. Aus dem Sberbank-»KMU Wachstumsindex" wird deutlich, dass nicht einmal die Hälfte der verschuldeten KMUs in der Lage ist, jene nun zurückzuzahlen. Und obgleich der Aussetzung der Insolvenzregeln für KMUs im Zuge der Pandemie schloss bis August 2020 knapp jedes fünfte KMU. Parallel dazu kamen zwar neue Unternehmensgründungen, jedoch schlug der Nettoverlust an Unternehmen dieser Art in diesem Zeitraum mit knapp 4,2 \% zu Buche.

Nichtsdestotrotz hellte sich die Situation der KMUs im Zuge der zweiten und dritten Pandemiewelle auf, was in erster Linie auf das weitgehende Ausbleiben von pandemiebedingten Einschränkungen in Russland zurückgeführt werden kann. Die Öffnung der Wirtschaft inmitten einer Pandemie kann dabei als Weg gesehen werden, den heimischen Konsum, das Hauptproblem der KMUs, zu stärken, insbesondere in einer Lage, in der der Kreml nicht gewillt ist, größere Stimuli auf den Weg zu bringen und den Unternehmen augenscheinlich das Vertrauen in die Regierung fehlt, jene anzunehmen. Der Nachteil dieser Politik liegt jedoch auf der Hand, nämlich viele Todesfälle und ungeahnte Langzeitfolgen für Betroffene. Die tatsächliche Übersterblichkeit in Russland während der Pandemie wird dementsprechend von verschiedenen, unabhängigen Stellen auf 400.000 bis 600.000 Toten beziffert, was einen der höchsten Werte weltweit darstellt.

Die aktuellen Maßnahmen und das damit verbundene Rückgreifen vieler KMUs auf Kredite führen somit viele dieser Unternehmen vor die langfristige Zahlungsunfähigkeit. Besonders weil viele KMUs bereits vor der Pandemie zu kämpfen hatten und die Probleme durch die Krise und die spärliche Antwort darauf von Seiten des Kremls potenziert wurden. Eine Negativspirale ist seit längerer Zeit im Gange und wenig deutet auf einen Ausbruch daraus hin. Auch im ersten Quartal 2021 sanken die real verfügbaren Einkommen der Bevölkerung um 3,6 \%, was das achte Jahr des Rückgangs in Folge darstellt. Der Grund dafür ist im politischen System selbst zu finden. Sollten keine tiefgreifenden Systemreformen kommen, so wird die durch die Corona-Pandemie gestiegene Schuldenlast für viele KMUs den Tod auf Raten bedeuten. nächsten Seite. 
Über den Autor:

Michael Martin Richter ist wissenschaftlicher Mitarbeiter der Forschungsstelle Osteuropa (FSO) an der Universität Bremen sowie Doktorand der Bremen International Graduate School of Social Sciences (BIGSSS).

Der Beitrag wurde im Rahmen des von der EU finanzierten Innovativen Trainingsnetzwerks "MARKETS « verfasst und stellt ausschließlich die Meinung des Autors dar.

\section{Lesetipps:}

- Åslund, Anders. Russia’s Crony Capitalism. Yale University Press, 2019.

- Belton, Catherine. Putin's people: how the KGB took back Russia and then took on the West. Farrar, Straus and Giroux, 2020.

- Dawisha, Karen. Putin’s kleptocracy: who owns Russia?. Simon and Schuster, 2015.

- Miller, Chris. Putinomics: Power and money in resurgent Russia. UNC Press Books, 2018.

- Sakwa, Richard. Putin redux: Power and contradiction in contemporary Russia. Routledge, 2014

\section{STATISTIK}

\section{Covid-19 in Russland, Stand 24. Juni 2021}

Die Covid-19-Statistik wird nach dem Ende der Sommerpause eingestellt. Interessierte Leser_innen können sich über den Verlauf der Covid-19-Pandemie in Russland unter Verwendung entsprechender Filter auffolgenden Seiten im Internet informieren: https://coronavirus. jhu.edu/map.html, https://github.com/CSSEGISandData/COVID-19/blob/master/csse_covid_19_data/csse_covid_19_time_ series/time_series_covid19_confirmed_global.csv, https://github.com/CSSEGISandData/COVID-19/blob/master/csse_covid_19_ data/csse_covid_19_time_series/time_series_covid19_deaths_global.csv, https://github.com/owid/covid-19-data/blob/master/ public/data/vaccinations/country_data/Russia.csv.

Grafik 1: Ausbreitung von Covid-19 in Russland (tägliche Fallzahlen, 01. März 2020 - 24. Juni 2021)

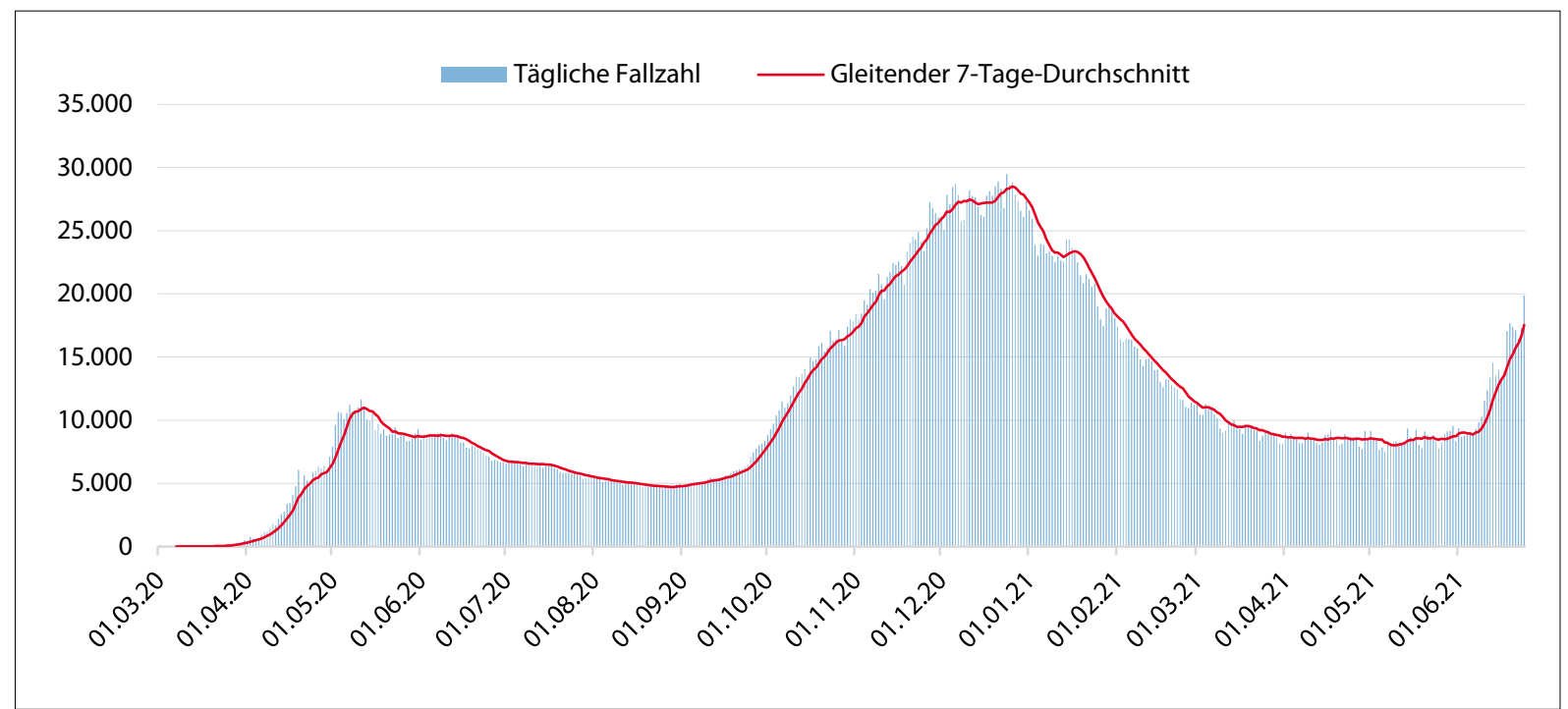

Die detaillierten Werte vom 01.03.2020-14.05.2021 können in der Statistik »Covid-19 in Russland» in den Russland-Analysen 393-402 eingesehen werden. Experten gehen davon aus, dass die offiziellen Zahlen um ein Vielfaches zu niedrig ausfallen. Die Dunkelziffer kann im Fall der Todesfälle anhand der Übersterblichkeit geschätzt werden. Die/der Leser/in sei auch auf die Texte und Statistiken auf den S. 2-26 in den Russland-Analysen 400 (https://www.laenderanalysen.de/russland-analysen/400/) verwiesen. Die offiziellen Zahlen geben aber die öffentlich kommunizierte Einschätzung und Entwicklung der epidemiologischen Lage wieder, weshalb wir uns als Redaktion entschlossen haben, sie an dieser Stelle zu veröffentlichen.

Quelle: Johns Hopkins Universität. Stand: 24.06.2021, 12:22 Uhr MESZ https://coronavirus.jhu.edu/map.html; https://github.com/CSSEGISandData/ COVID-19/blob/master/csse_covid_19_data/csse_covid_19_time_series/time_series_covid19_confirmed_global.csv 
Tabelle 1:Ausbreitung von Covid-19 in Russland (Fälle, 15. Mai - 24. Juni 2021)

\begin{tabular}{|c|c|c|}
\hline Datum & Gesamtzahl der Fälle & Tägliche Fälle \\
\hline 15.05 .21 & 4.875 .308 & 8.667 \\
16.05 .21 & 4.883 .734 & 8.426 \\
17.05 .21 & 4.892 .938 & 9.204 \\
18.05 .21 & 4.900 .995 & 8.057 \\
19.05 .21 & 4.908 .794 & 7.799 \\
20.05 .21 & 4.917 .906 & 9.112 \\
21.05 .21 & 4.926 .717 & 8.811 \\
22.05 .21 & 4.935 .302 & 8.585 \\
23.05 .21 & 4.944 .129 & 8.827 \\
24.05 .21 & 4.952 .412 & 8.283 \\
25.05 .21 & 4.960 .174 & 7.762 \\
26.05 .21 & 4.968 .421 & 8.247 \\
27.05 .21 & 4.977 .332 & 8.911 \\
28.05 .21 & 4.986 .458 & 9.126 \\
29.05 .21 & 4.995 .613 & 9.155 \\
30.05 .21 & 5.005 .171 & 9.558 \\
31.05 .21 & 5.013 .512 & 8.341 \\
01.06 .21 & 5.022 .881 & 9.369 \\
02.06 .21 & 5.031 .583 & 8.702 \\
03.06 .21 & 5.040 .390 & 8.807 \\
04.06 .21 & 5.049 .210 & 8.820 \\
\hline
\end{tabular}

\begin{tabular}{|c|c|c|}
\hline Datum & Gesamtzahl der Fälle & Tägliche Fälle \\
\hline 05.06 .21 & 5.058 .221 & 9.011 \\
06.06 .21 & 5.067 .246 & 9.025 \\
07.06 .21 & 5.076 .543 & 9.297 \\
08.06 .21 & 5.086 .386 & 9.843 \\
09.06 .21 & 5.096 .657 & 10.271 \\
10.06 .21 & 5.108 .217 & 11.560 \\
11.06 .21 & 5.120 .578 & 12.361 \\
12.06 .21 & 5.133 .938 & 13.360 \\
13.06 .21 & 5.148 .499 & 14.561 \\
14.06 .21 & 5.162 .049 & 13.550 \\
15.06 .21 & 5.176 .051 & 14.002 \\
16.06 .21 & 5.189 .260 & 13.209 \\
17.06 .21 & 5.203 .117 & 13.857 \\
18.06 .21 & 5.220 .168 & 17.051 \\
19.06 .21 & 5.237 .847 & 17.679 \\
20.06 .21 & 5.255 .214 & 17.367 \\
21.06 .21 & 5.272 .328 & 17.114 \\
22.06 .21 & 5.288 .766 & 16.438 \\
23.06 .21 & 5.306 .069 & 17.303 \\
24.06 .21 & 5.325 .940 & 19.871 \\
\hline
\end{tabular}

Die detaillierten Werte vom 01.03.2020-14.05.2021 können in der Statistik "Covid-19 in Russland in den Russland-Analysen 393-402 eingesehen werden. Experten gehen davon aus, dass die offiziellen Zahlen um ein Vielfaches zu niedrig ausfallen. Die Dunkelziffer kann im Fall der Todesfälle anhand der Übersterblichkeit geschätzt werden. Die/der Leser/in sei auch auf die Texte und Statistiken auf den S. 2-26 in den Russland-Analysen 400 (https://www.laenderanalysen.de/russland-analysen/400/) verwiesen. Die offiziellen Zahlen geben aber die öffentlich kommunizierte Einschätzung und Entwicklung der epidemiologischen Lage wieder, weshalb wir uns als Redaktion entschlossen haben, sie an dieser Stelle zu veröffentlichen.

Quelle: Johns Hopkins Universität. Stand: 24.06.2021, 12:22 Uhr MESZ https://coronavirus.jhu.edu/map.html; https://github.com/CSSEGISandData/ COVID-19/blob/master/csse_covid_19_data/csse_covid_19_time_series/time_series_covid19_confirmed_global.csv

Grafik 2: Todesfälle durch Covid-19 in Russland (tägliche Todesfälle, 01. März 2020 - 24. Juni 2021)

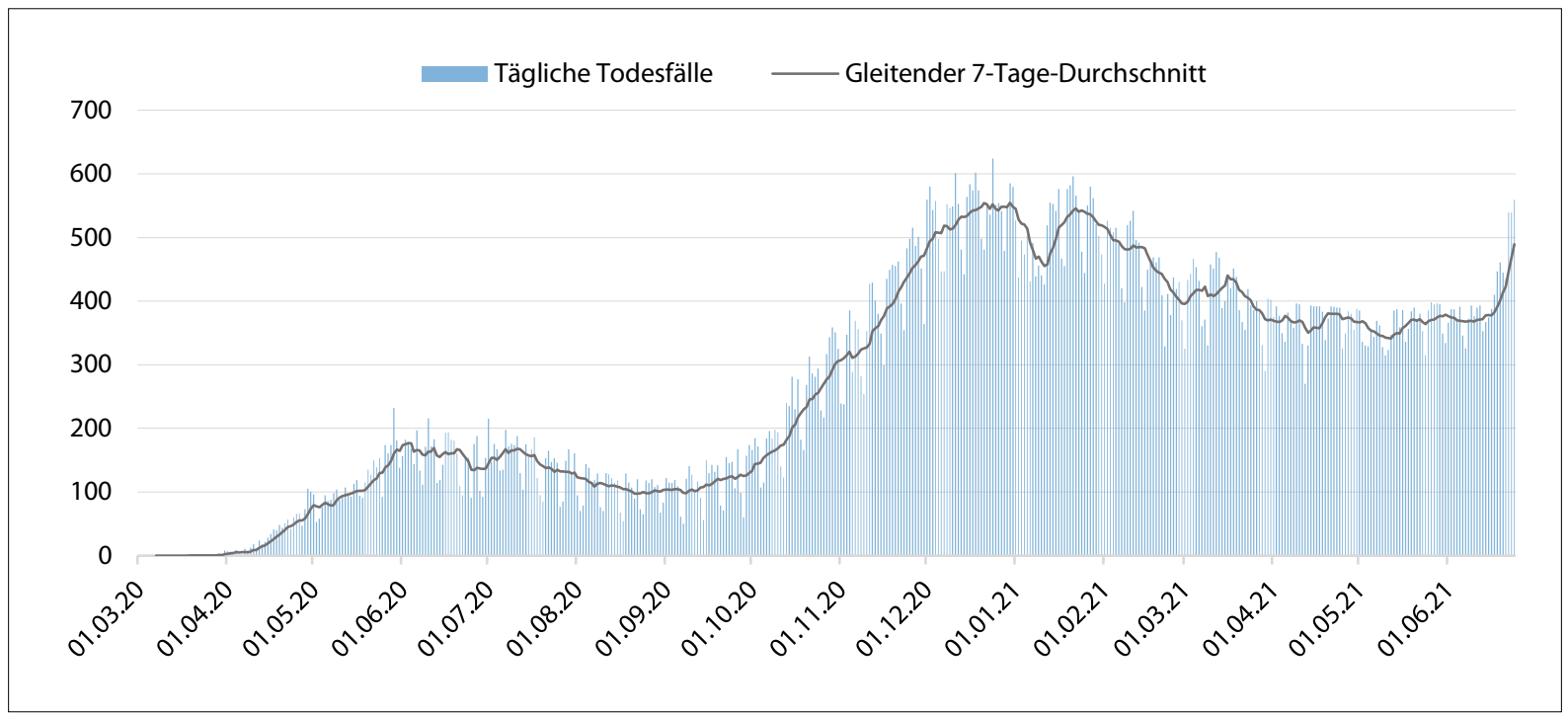

Die detaillierten Werte vom 01.03.2020-14.05.2021 können in der Statistik „Covid-19 in Russland in den Russland-Analysen 393-402 eingesehen werden.

Experten gehen davon aus, dass die offiziellen Zahlen um ein Vielfaches zu niedrig ausfallen. Die Dunkelziffer kann im Fall der Todesfälle anhand der Übersterblichkeit geschätzt werden. Die/der Leser/in sei auch auf die Texte und Statistiken aufden S. 2-26 in den Russland-Analysen 400 (https://www.laenderanalysen.de/russland-analysen/400/) verwiesen. Die offiziellen Zahlen geben aber die öffentlich kommunizierte Einschätzung und Entwicklung der epidemiologischen Lage wieder, weshalb wir uns als Redaktion entschlossen haben, sie an dieser Stelle zu veröffentlichen.

Quelle: Johns Hopkins Universität. Stand: 24.06.2021, 12:22 Uhr MESZ https://coronavirus.jhu.edu/map.html; https://github.com/CSSEGISandData/ COVID-19/blob/master/csse_covid_19_data/csse_covid_19_time_series/time_series_covid19_deaths_global.csv 
Tabelle 2: Todesfälle durch Covid-19 in Russland (15. Mai - 24. Juni 2021)

\begin{tabular}{|c|c|c|}
\hline Datum & $\begin{array}{c}\text { Gesamtzahl der } \\
\text { Todesfälle }\end{array}$ & Tägliche Todesfälle \\
\hline 15.05 .21 & 113.541 & 359 \\
16.05 .21 & 113.927 & 386 \\
17.05 .21 & 114.263 & 336 \\
18.05 .21 & 114.619 & 356 \\
19.05 .21 & 115.003 & 384 \\
20.05 .21 & 115.393 & 390 \\
21.05 .21 & 115.764 & 371 \\
22.05 .21 & 116.144 & 380 \\
23.05 .21 & 116.497 & 353 \\
24.05 .21 & 116.812 & 315 \\
25.05 .21 & 117.197 & 385 \\
26.05 .21 & 117.595 & 398 \\
27.05 .21 & 117.990 & 395 \\
28.05 .21 & 118.386 & 396 \\
29.05 .21 & 118.781 & 395 \\
30.05 .21 & 119.130 & 349 \\
31.05 .21 & 119.464 & 334 \\
01.06 .21 & 119.830 & 366 \\
\hline 02.06 .21 & 120.217 & 387 \\
03.06 .21 & 120.604 & 387 \\
04.06 .21 & 120.974 & 370 \\
\hline
\end{tabular}

\begin{tabular}{|c|c|c|}
\hline Datum & $\begin{array}{c}\text { Gesamtzahl der } \\
\text { Todesfälle }\end{array}$ & Tägliche Todesfälle \\
\hline 05.06 .21 & 121.365 & 391 \\
06.06 .21 & 121.711 & 346 \\
07.06 .21 & 122.037 & 326 \\
08.06 .21 & 122.409 & 372 \\
09.06 .21 & 122.802 & 393 \\
10.06 .21 & 123.178 & 376 \\
11.06 .21 & 123.568 & 390 \\
12.06 .21 & 123.961 & 393 \\
13.06 .21 & 124.314 & 353 \\
14.06 .21 & 124.681 & 367 \\
15.06 .21 & 125.055 & 374 \\
16.06 .21 & 125.443 & 388 \\
17.06 .21 & 125.853 & 410 \\
18.06 .21 & 126.300 & 447 \\
19.06 .21 & 126.761 & 461 \\
20.06 .21 & 127.206 & 445 \\
21.06 .21 & 127.641 & 435 \\
22.06 .21 & 128.180 & 539 \\
23.06 .21 & 128.719 & 539 \\
24.06 .21 & 129.278 & 559 \\
\hline
\end{tabular}

Die detaillierten Werte vom 01.03.2020-14.05.2021 können in der Statistik "Covid-19 in Russland« in den Russland-Analysen 393-402 eingesehen werden. Experten gehen davon aus, dass die offiziellen Zahlen um ein Vielfaches zu niedrig ausfallen. Die Dunkelziffer kann im Fall der Todesfälle anhand der Übersterblichkeit geschätzt werden. Die/der Leser/in sei auch auf die Texte und Statistiken auf den S. 2-26 in den Russland-Analysen 400 (https://www.laenderanalysen.de/russland-analysen/400/) verwiesen . Die offiziellen Zahlen geben aber geben die öffentlich kommunizierte Einschätzung und Entwicklung der epidemiologischen Lage wieder, weshalb wir uns als Redaktion entschlossen haben, sie an dieser Stelle zu veröffentlichen.

Quelle: Johns Hopkins Universität. Stand: 24.06.2021, 12:22 Uhr MESZ https://coronavirus.jhu.edu/map.html; https://github.com/CSSEGISandData/ COVID-19/blob/master/csse_covid_19_data/csse_covid_19_time_series/time_series_covid19_deaths_global.csv

\section{Grafik 3: Anzahl der Impfungen gegen Covid-19 in Russland (24. Juni 2021)}

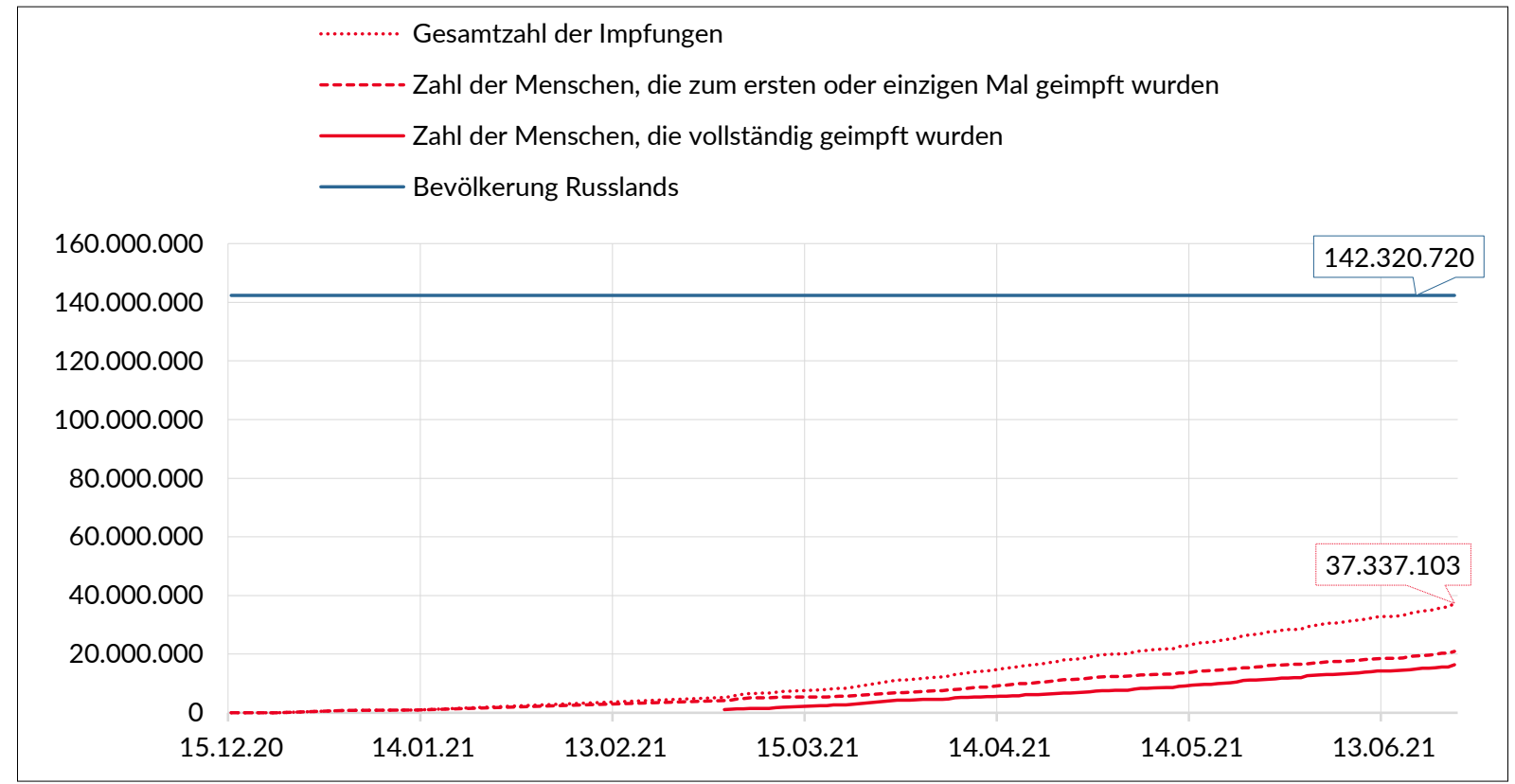

Verimpfte Impfstoffe: Sputnik V, EpiVacCorona

Quelle: https://github.com/owid/covid-19-data/blob/master/public/data/vaccinations/country_data/Russia.csv, unter Verwendung von Daten von http://government.ru/news/41122/, https://tass.com/society/1238521, https://tass.com/society/1241979, https://twitter.com/redouad/ status/1350030539944820736, https://gogov.ru/articles/covid-v-stats 
Grafik 4: Anteil der russischen Bevölkerung, der vollständig gegen Covid-19 geimpft wurde (24. Juni 2021)

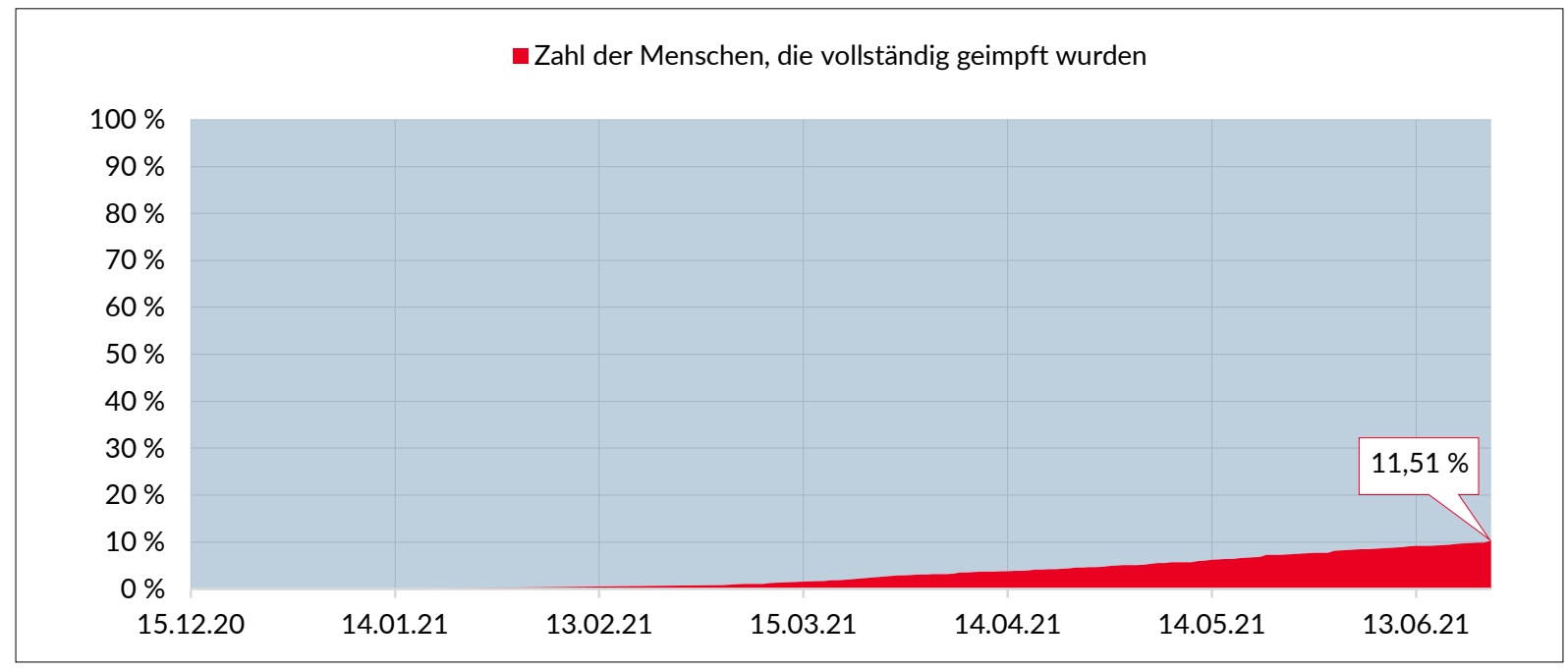

Verimpfte Impfstoffe: Sputnik V, EpiVacCorona

Quelle: https://github.com/owid/covid-19-data/blob/master/public/data/vaccinations/country_data/Russia.csv, unter Verwendung von Daten von http://government.ru/news/41122/, https://tass.com/society/1238521, https://tass.com/society/1241979, https://twitter.com/redouad/ status/1350030539944820736, https://gogov.ru/articles/covid-v-stats

\section{CHRONIK}

\section{Covid-19-Chronik, 03. - 30. Mai 2021}

\begin{tabular}{|c|c|}
\hline 03.05 .2021 & $\begin{array}{l}\text { Die Zahl der offiziell bestätigten Coronavirus-Infektionen ist in Russland innerhalb der vergangenen } 24 \text { Stun- } \\
\text { den um } 8.489 \text { auf insgesamt } 4.831 .744 \text { angestiegen. Offiziell gibt es seit Beginn der Pandemie 111.198 Todes- } \\
\text { fälle. Den höchsten Zuwachs verzeichnet Moskau mit 2.635 neuen Fällen innerhalb von } 24 \text { Stunden. }\end{array}$ \\
\hline 04.05 .2021 & $\begin{array}{l}\text { Die Zahl der offiziell bestätigten Coronavirus-Infektionen ist in Russland innerhalb der vergangenen } 24 \text { Stun- } \\
\text { den um } 7.770 \text { auf insgesamt } 4.839 .514 \text { angestiegen. Dies ist der niedrigste Zuwachs seit Ende September } 2020 \text {. } \\
\text { Offiziell gibt es seit Beginn der Pandemie } 111.535 \text { Todesfälle. Den höchsten Zuwachs verzeichnet Moskau mit } \\
2.050 \text { neuen Fällen innerhalb von } 24 \text { Stunden. }\end{array}$ \\
\hline 05.05 .2021 & $\begin{array}{l}\text { Die Zahl der offiziell bestätigten Coronavirus-Infektionen ist in Russland innerhalb der vergangenen } 24 \text { Stun- } \\
\text { den um } 7.975 \text { auf insgesamt } 4.847 .489 \text { angestiegen. Offiziell gibt es seit Beginn der Pandemie } 111.895 \text { Todes- } \\
\text { fälle. Den höchsten Zuwachs verzeichnet Moskau mit } 2.432 \text { neuen Fällen innerhalb von } 24 \text { Stunden. }\end{array}$ \\
\hline 06.05 .2021 & $\begin{array}{l}\text { Die Zahl der offiziell bestätigten Coronavirus-Infektionen ist in Russland innerhalb der vergangenen } 24 \text { Stun- } \\
\text { den um } 7.639 \text { auf insgesamt } 4.855 .128 \text { angestiegen. Offiziell gibt es seit Beginn der Pandemie 112.246 Todes- } \\
\text { fälle. Den höchsten Zuwachs verzeichnet Moskau mit } 2.114 \text { neuen Fällen innerhalb von } 24 \text { Stunden. }\end{array}$ \\
\hline 06.05 .2021 & $\begin{array}{l}\text { Das russische Gesundheitsministerium lässt den vom "Gamaleja-Institut» entwickelten Covid-19-Impfstoff } \\
\text { „Sputnik light« zu. Das Vakzin muss zur Entfaltung der vollen Wirkung nur einmal verabreicht werden, die } \\
\text { Immunität besteht allerdings nur etwa ein halbes Jahr. Es soll in besonders betroffenen Gebieten eingesetzt } \\
\text { werden, um eine schnelle Immunität der Bevölkerung zu erreichen. }\end{array}$ \\
\hline 06.05 .2021 & $\begin{array}{l}\text { Die stellvertretende russische Ministerpräsidentin Tatjana Golikowa gibt bekannt, dass nur noch in vier rus- } \\
\text { sischen Regionen die Ansteckungszahlen mit Covid-19 wachsen. In } 32 \text { Regionen seien die Zahlen rückläufig. } \\
\text { Die landesweite Sieben-Tage-Inzidenz läge zurzeit bei } 41,3 \text { je } 100.000 \text { Einwohner:innen. }\end{array}$ \\
\hline 07.05 .2021 & $\begin{array}{l}\text { Die Zahl der offiziell bestätigten Coronavirus-Infektionen ist in Russland innerhalb der vergangenen } 24 \text { Stun- } \\
\text { den um } 8.386 \text { auf insgesamt } 4.863 .514 \text { angestiegen. Offiziell gibt es seit Beginn der Pandemie 112.622 Todes- } \\
\text { fälle. Den höchsten Zuwachs verzeichnet Moskau mit } 2.846 \text { neuen Fällen innerhalb von } 24 \text { Stunden. }\end{array}$ \\
\hline
\end{tabular}




\begin{tabular}{|c|c|}
\hline 08.05 .2021 & $\begin{array}{l}\text { Die Zahl der offiziell bestätigten Coronavirus-Infektionen ist in Russland innerhalb der vergangenen } 24 \text { Stun- } \\
\text { den um } 8.329 \text { auf insgesamt } 4.871 .843 \text { angestiegen. Offiziell gibt es seit Beginn der Pandemie } 112.992 \text { Todes- } \\
\text { fälle. Den höchsten Zuwachs verzeichnet Moskau mit } 2.765 \text { neuen Fällen innerhalb von } 24 \text { Stunden. }\end{array}$ \\
\hline 09.05 .2021 & $\begin{array}{l}\text { Die Zahl der offiziell bestätigten Coronavirus-Infektionen ist in Russland innerhalb der vergangenen } 24 \text { Stun- } \\
\text { den um } 8.419 \text { auf insgesamt } 4.880 .262 \text { angestiegen. Offiziell gibt es seit Beginn der Pandemie } 113.326 \text { Todes- } \\
\text { fälle. Den höchsten Zuwachs verzeichnet Moskau mit } 2.828 \text { neuen Fällen innerhalb von } 24 \text { Stunden. }\end{array}$ \\
\hline 10.05 .2021 & $\begin{array}{l}\text { Die Zahl der offiziell bestätigten Coronavirus-Infektionen ist in Russland innerhalb der vergangenen } 24 \text { Stun- } \\
\text { den um } 8.465 \text { auf insgesamt } 4.888 .727 \text { angestiegen. Offiziell gibt es seit Beginn der Pandemie 113.647 Todes- } \\
\text { fälle. Den höchsten Zuwachs verzeichnet Moskau mit } 2.896 \text { neuen Fällen innerhalb von } 24 \text { Stunden. }\end{array}$ \\
\hline 11.05 .2021 & $\begin{array}{l}\text { In der Republik Sacha (Jakutien) bleiben Unterhaltungs- und Freizeiteinrichtungen ab sofort geschlossen. } \\
\text { Außerdem wird Schulunterricht bis zur achten Klasse als Fernunterricht stattfinden. Diese Maßnahme soll } \\
\text { der Eindämmung der Conoravirus-Pandemie dienen. In Jakutien wurden in den vergangenen } 24 \text { Stunden } 112 \\
\text { neue Covid-19-Infektionen festgestellt. }\end{array}$ \\
\hline 11.05 .2021 & $\begin{array}{l}\text { Die Zahl der offiziell bestätigten Coronavirus-Infektionen ist in Russland innerhalb der vergangenen } 24 \text { Stun- } \\
\text { den um } 8.115 \text { auf insgesamt } 4.896 .842 \text { angestiegen. Offiziell gibt es seit Beginn der Pandemie } 113.976 \text { Todes- } \\
\text { fälle. Den höchsten Zuwachs verzeichnet Moskau mit } 2.628 \text { neuen Fällen innerhalb von } 24 \text { Stunden. }\end{array}$ \\
\hline 12.05 .2021 & $\begin{array}{l}\text { Die Zahl der offiziell bestätigten Coronavirus-Infektionen ist in Russland innerhalb der vergangenen } 24 \text { Stun- } \\
\text { den um } 8.217 \text { auf insgesamt } 4.905 .059 \text { angestiegen. Offiziell gibt es seit Beginn der Pandemie } 114.331 \text { Todes- } \\
\text { fälle. Den höchsten Zuwachs verzeichnet Moskau mit } 2.718 \text { neuen Fällen innerhalb von } 24 \text { Stunden. }\end{array}$ \\
\hline 12.05 .2021 & $\begin{array}{l}\text { Der Gouverneur von Sankt Petersburg, Aleksandr Beglow, gibt bekannt, dass die Sozialausgaben des städti- } \\
\text { schen Haushalts im Jahr } 2020 \text { im Vergleich zum Vorjahr um fast } 30 \text { Prozent gestiegen sind. Rund } 77 \text { Milliarden } \\
\text { Rubel (etwa } 855 \text { Millionen Euro) fielen für die Unterstützung der Bevölkerung in der Covid-19-Pandemie an. }\end{array}$ \\
\hline 13.05 & $\begin{array}{l}\text { Die Zahl der offiziell bestätigten Coronavirus-Infektionen ist in Russland innerhalb der vergangenen } 24 \text { Stun- } \\
\text { den um } 8.380 \text { auf insgesamt } 4.913 .439 \text { angestiegen. Offiziell gibt es seit Beginn der Pandemie } 114.723 \text { Todes- } \\
\text { fälle. Den höchsten Zuwachs verzeichnet Moskau mit } 2.787 \text { neuen Fällen innerhalb von } 24 \text { Stunden. }\end{array}$ \\
\hline 13.05.2021 & Die Malediven lassen den in Russland entwickelten Covid-19-Impfstoff »Sputnik V«zu. \\
\hline 14.05 .2021 & $\begin{array}{l}\text { Die Zahl der offiziell bestätigten Coronavirus-Infektionen ist in Russland innerhalb der vergangenen } 24 \text { Stun- } \\
\text { den um } 9.462 \text { auf insgesamt 4.922.901 angestiegen. Offiziell gibt es seit Beginn der Pandemie 115.116 Todes- } \\
\text { fälle. Den höchsten Zuwachs verzeichnet Moskau mit } 3.818 \text { neuen Fällen innerhalb von } 24 \text { Stunden. }\end{array}$ \\
\hline 14.05 .2021 & $\begin{array}{l}\text { Der vom staatlichen Forschungszentrum für Virologie und Biotechnologie "Vektor« entwickelte Covid-19- } \\
\text { Impfstoff »EpiVakCorona«steht ab sofort in den Impfzentren in Moskau zur Verfügung. Dies teilte die stell- } \\
\text { vertretende Moskauer Bürgermeisterin Anastassija Rakowa mit. Bisher wurde ausschließlich der vom »Gama- } \\
\text { leja-Institut« entwickelte Impfstoff »Sputnik V« verimpft. }\end{array}$ \\
\hline 14.05 .2021 & $\begin{array}{l}\text { Russland nimmt ab dem 25. Mai } 2021 \text { den Flugverkehr mit Island, Malta, Mexiko, Portugal und Saudi-Ara- } \\
\text { bien wieder auf. Dieser war im März } 2020 \text { aufgrund der Ausbreitung des Coronavirus ausgesetzt worden. }\end{array}$ \\
\hline 15.05.2021 & $\begin{array}{l}\text { Die Zahl der offiziell bestätigten Coronavirus-Infektionen ist in Russland innerhalb der vergangenen } 24 \text { Stun- } \\
\text { den um } 8.790 \text { auf insgesamt } 4.931 .691 \text { angestiegen. Offiziell gibt es seit Beginn der Pandemie } 115.480 \text { Todes- } \\
\text { fälle. Den höchsten Zuwachs verzeichnet Moskau mit } 3.073 \text { neuen Fällen innerhalb von } 24 \text { Stunden. }\end{array}$ \\
\hline 15.05 .2021 & $\begin{array}{l}\text { Ecuador lässt den in Russland entwickelten Covid-19-Impfstoff "Sputnik V« zu. Außerdem wurde der eben- } \\
\text { falls vom "Gamaleja-Institut« entwickelte Impfstoff "Sputnik light« bereits in Venezuela, Angola und Bahrain } \\
\text { zugelassen. »Sputnik light« ist bereits nach der ersten Dosis voll wirksam, der Schutz hält allerdings nur etwa } \\
\text { sechs Monate an. Nach Vorstellung des "Gamaleja-Instituts« soll er in Hochinzidenzgebieten eingesetzt wer- } \\
\text { den, um eine schnelle Herdenimmunität zu erreichen. }\end{array}$ \\
\hline 15.05 .2021 & $\begin{array}{l}\text { Die Zahl der offiziell bestätigten Coronavirus-Infektionen ist in Russland innerhalb der vergangenen } 24 \text { Stun- } \\
\text { den um } 8.554 \text { auf insgesamt } 4.940 .245 \text { angestiegen. Offiziell gibt es seit Beginn der Pandemie } 115.871 \text { Todes- } \\
\text { fälle. Den höchsten Zuwachs verzeichnet Moskau mit } 2.789 \text { neuen Fällen innerhalb von } 24 \text { Stunden. }\end{array}$ \\
\hline 17.05 .2021 & $\begin{array}{l}\text { Die Zahl der offiziell bestätigten Coronavirus-Infektionen ist in Russland innerhalb der vergangenen } 24 \text { Stun- } \\
\text { den um } 9.328 \text { auf insgesamt } 4.949 .573 \text { angestiegen. Offiziell gibt es seit Beginn der Pandemie } 116.211 \text { Todes- } \\
\text { fälle. Den höchsten Zuwachs verzeichnet Moskau mit } 3.573 \text { neuen Fällen innerhalb von } 24 \text { Stunden. }\end{array}$ \\
\hline 17.05.2021 & $\begin{array}{l}\text { In den städtischen Krankenhäusern von Sankt Petersburg werden weitere } 459 \text { Betten für die Behandlung von } \\
\text { Covid-19-Patienten zur Verfügung gestellt. Begründet wurde diese Maßnahme mit den steigenden Fallzah- } \\
\text { len in der Stadt. }\end{array}$ \\
\hline
\end{tabular}




\begin{tabular}{|c|c|}
\hline 18.05 .2021 & $\begin{array}{l}\text { Die Zahl der offiziell bestätigten Coronavirus-Infektionen ist in Russland innerhalb der vergangenen } 24 \text { Stun- } \\
\text { den um } 8.183 \text { auf insgesamt } 4.957 .756 \text { angestiegen. Offiziell gibt es seit Beginn der Pandemie } 116.575 \text { Todes- } \\
\text { fälle. Den höchsten Zuwachs verzeichnet Moskau mit } 2.430 \text { neuen Fällen innerhalb von } 24 \text { Stunden. }\end{array}$ \\
\hline 19.05 .2021 & $\begin{array}{l}\text { Der russische Außenminister Sergej Lawrow sagt seinem tadschikischen Amtskollegen Sirdjiddin Muchiddin } \\
\text { die kostenlose Lieferung des in Russland entwickelten Covid-19-Impfstoffs "Sputnik V« zu. Dies sei Teil der } \\
\text { anlässlich eines Treffens der Präsidenten beider Länder am 8. Mai } 2021 \text { in Moskau getroffenen Vereinbarung. }\end{array}$ \\
\hline 19.05 .2021 & $\begin{array}{l}\text { Die Zahl der offiziell bestätigten Coronavirus-Infektionen ist in Russland innerhalb der vergangenen } 24 \text { Stun- } \\
\text { den um } 7.920 \text { auf insgesamt 4.965.676 angestiegen. Offiziell gibt es seit Beginn der Pandemie 116.965 Todes- } \\
\text { fälle. Den höchsten Zuwachs verzeichnet Moskau mit } 2.096 \text { neuen Fällen innerhalb von } 24 \text { Stunden. }\end{array}$ \\
\hline 19.05 .2021 & $\begin{array}{l}\text { ach Angaben des russischen Gesundheitsministeriums erkrankten in Russland seit Beginn der Covid-19-Pan- } \\
\text { mie rund 560.000 Kinder an dem Virus. } 112.000 \text { wurden stationär behandelt. }\end{array}$ \\
\hline 20.05 .2021 & $\begin{array}{l}\text { Die Zahl der offiziell bestätigten Coronavirus-Infektionen ist in Russland innerhalb der vergangenen } 24 \text { Stun- } \\
\text { den um } 9.232 \text { auf insgesamt } 4.974 .908 \text { angestiegen. Offiziell gibt es seit Beginn der Pandemie } 117.361 \text { Todes- } \\
\text { fälle. Den höchsten Zuwachs verzeichnet Moskau mit } 3.312 \text { neuen Fällen innerhalb von } 24 \text { Stunden. }\end{array}$ \\
\hline 20.05 . & $\begin{array}{l}\text { Der russische Ministerpräsident Michail Mischustin gibt bekannt, dass im Jahr } 2021 \text { Ausgaben in Höhe von } \\
26 \text { Milliarden Rubel (etwa } 289 \text { Millionen Euro) für die Impfung der russischen Bevölkerung gegen Covid-19 } \\
\text { geplant sind. Er betonte, dass die Impfungen fortgesetzt werden sollen, bis eine Herdenimmunität erreicht ist. }\end{array}$ \\
\hline 20.05 .2021 & $\begin{array}{l}\text { Die russische Verbraucherschutzbehörde "Rospotrebnadsor» beobachtet die verstärkte Verbreitung der bri- } \\
\text { tischen Mutation des Coronavirus in Russland. Zwischen den Maifeiertagen sei in } 401 \text { Proben die britische } \\
\text { Mutante nachgewiesen worden. }\end{array}$ \\
\hline 21.0 & $\begin{array}{l}\text { Der Moskauer Bürgermeister Sergej Sobjanin gibt bekannt, dass in den Krankenhäusern der Stadt zurzeit rund } \\
9.000 \text { an Covid-19 erkrankte Menschen behandelt werden. Außerdem betonte er, dass sich jeder impfwillige } \\
\text { Einwohner der Stadt gegen Covid-19 impfen lassen könne. Die Zahl der Geimpften ist in Moskau, nach Aus- } \\
\text { sagen Sobjanins, geringer als in jeder anderen europäischen Großstadt. }\end{array}$ \\
\hline 21.05 & $\begin{array}{l}\text { Die Zahl der offiziell bestätigten Coronavirus-Infektionen ist in Russland innerhalb der vergangenen } 24 \text { Stun- } \\
\text { den um } 8.937 \text { auf insgesamt } 4.983 .845 \text { angestiegen. Offiziell gibt es seit Beginn der Pandemie } 117.739 \text { Todes- } \\
\text { fälle. Den höchsten Zuwachs verzeichnet Moskau mit } 2.954 \text { neuen Fällen innerhalb von } 24 \text { Stunden. }\end{array}$ \\
\hline 21.05 & $\begin{array}{l}\text { Der Moskauer Bürgermeister Sergej Sobjanin gibt bekannt, dass bisher 1,4 Millionen Einwohner der Haupt- } \\
\text { stadt die erste von zwei notwendigen Impfdosen gegen Covid-19 erhalten hätten. 1,3 Millionen Moskauer seien } \\
\text { bereits vollständig geimpft. Die Impfungen gegen Covid-19 begannen in Moskau Anfang Dezember } 2020 \text {. }\end{array}$ \\
\hline 21.05 & $\begin{array}{l}\text { Die aufgrund der Ausbreitung des Coronavirus geltenden Einschränkungen des öffentlichen Lebens in Sankt } \\
\text { Petersburg werden bis zum 12. Juli } 2021 \text { aufrechterhalten. Einen entsprechenden Erlass unterzeichnete Gou- } \\
\text { verneur Aleksandr Beglow. }\end{array}$ \\
\hline 22.0 & $\begin{array}{l}\text { Die Zahl der offiziell bestätigten Coronavirus-Infektionen ist in Russland innerhalb der vergangenen } 24 \text { Stun- } \\
\text { den um } 8.709 \text { auf insgesamt } 4.992 .554 \text { angestiegen. Offiziell gibt es seit Beginn der Pandemie } 118.125 \text { Todes- } \\
\text { fälle. Den höchsten Zuwachs verzeichnet Moskau mit } 2.653 \text { neuen Fällen innerhalb von } 24 \text { Stunden. }\end{array}$ \\
\hline 22.05 & $\begin{array}{l}\text { er russische Ministerpräsident Michail Mischustin gibt bekannt, dass der inländische Coronavirus-Impfstoff } \\
\text { putnik V« in fast } 70 \text { Ländern weltweit registriert wurde. }\end{array}$ \\
\hline 22.05 .2021 & $\begin{array}{l}\text { rriechenland verlängert die Einreiseerlaubnis für Russinnen und Russen, die gegen das Coronavirus geimpft, } \\
\text { egativ getestet oder von der Krankheit genesen sind bis 31. Mai. }\end{array}$ \\
\hline 23.05 .2021 & $\begin{array}{l}\text { Die Zahl der offiziell bestätigten Coronavirus-Infektionen übersteigt in Russland die Fünf-Millionen-Marke. } \\
\text { Innerhalb der vergangenen } 24 \text { Stunden ist die Zahl um } 8.951 \text { auf insgesamt } 5.001 .505 \text { gestiegen. Offiziell gibt } \\
\text { es seit Beginn der Pandemie } 118.482 \text { Todesfälle. Den höchsten Zuwachs verzeichnet Moskau mit } 2.924 \text { neuen } \\
\text { Fällen innerhalb von } 24 \text { Stunden. }\end{array}$ \\
\hline 24.05 . & $\begin{array}{l}\text { Mehr als zehn Millionen Menschen sind in Russland vollständig gegen das Coronavirus geimpft. Insgesamt } \\
\text { haben } 25 \text { Millionen Menschen in Russland eine Impfdosis erhalten. Die Impfbereitschaft gilt in Russland als } \\
\text { sehr gering. }\end{array}$ \\
\hline 24.05 .2021 & $\begin{array}{l}\text { Die Zahl der offiziell bestätigten Coronavirus-Infektionen ist in Russland innerhalb der vergangenen } 24 \text { Stun- } \\
\text { den um } 8.406 \text { auf insgesamt 5.009.911 angestiegen. Offiziell gibt es seit Beginn der Pandemie } 118.801 \text { Todes- } \\
\text { fälle. Den höchsten Zuwachs verzeichnet Moskau mit } 2.487 \text { neuen Fällen innerhalb von } 24 \text { Stunden. }\end{array}$ \\
\hline 24.05 .2021 & $\begin{array}{l}\text { Das griechische Außenministerium erklärt in Bezug auf die Coronavirus-Pandemie, dass mit "Sputnik V« } \\
\text { geimpfte Reisende keine Probleme bei der Einreise nach Griechenland haben werden. }\end{array}$ \\
\hline
\end{tabular}




\begin{tabular}{|c|c|}
\hline 24.05 .2021 & $\begin{array}{l}\text { In Indien beginnt die Produktion des russischen Impfstoffs »Sputnik V«, der gegen eine Covid-19-Infektion } \\
\text { schützt. }\end{array}$ \\
\hline 25.05 .2021 & $\begin{array}{l}\text { Die Zahl der offiziell bestätigten Coronavirus-Infektionen ist in Russland innerhalb der vergangenen } 24 \text { Stun- } \\
\text { den um } 7.884 \text { auf insgesamt 5.017.795 gestiegen. Offiziell gibt es seit Beginn der Pandemie 119.194 Todesfälle. } \\
\text { Den höchsten Zuwachs verzeichnet Moskau mit } 2.075 \text { neuen Fällen innerhalb von } 24 \text { Stunden. }\end{array}$ \\
\hline 25.05 .2021 & $\begin{array}{l}\text { Russland verkauft laut dem Wirtschaftsmedium Forbes } 205 \text { Millionen Dosen des Covid-19-Vakzins "Sputnik } \\
\text { V« an } 45 \text { Staaten. Mehr als 16,3 Millionen Dosen seien bereits ausgeliefert worden, die größte Tranche mit 6,5 } \\
\text { Millionen Dosen ging demnach an Argentinien. }\end{array}$ \\
\hline 25.05 .2021 & $\begin{array}{l}\text { Die Regionalregierung der russischen Republik Sacha (ehemals Jakutien) verpflichtet einzelne Berufsgruppen } \\
\text { und Betriebsärztinnen und -ärzte zu Impfungen gegen das Coronavirus und droht bei Ablehnung mit Geld- } \\
\text { strafen von bis zu } 200.000 \text { Rubel (etwa } 2.200 \text { Euro). }\end{array}$ \\
\hline 25.05 .2021 & $\begin{array}{l}\text { Russland nimmt Flugverbindungen mit Island, Malta, Mexiko, Portugal und Saudi-Arabien wieder auf. Russ- } \\
\text { land erhöht zudem die Zahl der Flüge von und nach Südkorea, Finnland und Japan. Die Einschränkungen } \\
\text { wurden zuvor erlassen, um die weltweite Ausbreitung der Coronavirus-Pandemie einzuschränken. }\end{array}$ \\
\hline 26.05 .2021 & $\begin{array}{l}\text { Der russische Präsident Wladimir Putin sagt in einer Rede, die im Fernsehsender »Rossija 24« übertragen wird, } \\
\text { dass es in Russland keine Covid-19-Impfpflicht geben werde. }\end{array}$ \\
\hline 26.05 .2021 & $\begin{array}{l}\text { Die Regionalregierung der russischen Republik Sacha (ehemals Jakutien) dementiert eine Teil-Impfpflicht } \\
\text { gegen das Coronavirus vom Vortag. Es gebe keinen Zwang, sagt Gouverneur Aisen Nikolaew gegenüber der } \\
\text { staatlichen Nachrichtenagentur Tass. Gleichzeitig kritisiert er eine geringe Impfbereitschaft der Bevölkerung. }\end{array}$ \\
\hline 26.05 .2021 & $\begin{array}{l}\text { Die Zahl der offiziell bestätigten Coronavirus-Infektionen ist in Russland innerhalb der vergangenen } 24 \text { Stun- } \\
\text { den um } 8.373 \text { auf insgesamt 5.026.168 gestiegen. Offiziell gibt es seit Beginn der Pandemie 119.600 Todesfälle. } \\
\text { Den höchsten Zuwachs verzeichnet Moskau mit } 2.416 \text { neuen Fällen innerhalb von } 24 \text { Stunden. }\end{array}$ \\
\hline 26.05 .2021 & $\begin{array}{l}\text { Russland beginnt mit Massenimpfungen gegen das Coronavirus für Tiere und Haustiere. Das Vakzin "Corni- } \\
\text { vac-Cov«, das in Russland entwickelt und im April zugelassen wurde, sei in öffentlichen und privaten Veteri- } \\
\text { närkliniken erhältlich, teilte das staatliche Veterinäramt Rosselchosnadsor am Mittwoch mit. Das Amt bestä- } \\
\text { tigt den ersten Fall einer Coronavirusinfektion bei einer Hauskatze. }\end{array}$ \\
\hline 26.05 & $\begin{array}{l}\text { Die Slowakei erlaubt den Einsatz des russischen Covid-19-Vakzins »Sputnik V«. Spätestens ab 7. Juni sollen } \\
\text { Menschen in der Slowakei mit dem Vakzin geimpft werden. Die erste Charge von »Sputnik V« hatte das Land } \\
\text { am 1. März erhalten. }\end{array}$ \\
\hline 27.05 & $\begin{array}{l}\text { Russland und die Kinderhilfsorganisation UNICEF schließen einen Liefervertrag über } 220 \text { Millionen Dosen } \\
\text { des »Sputnik V«-Vakzins. Die Lieferung an die Organisation der Vereinten Nationen steht unter dem Vorbehalt, } \\
\text { dass der Covid-19-Impfstoff»Sputnik V« eine Notfallzulassung der Weltgesundheitsorganisation WHO erhält. }\end{array}$ \\
\hline 27.05 & $\begin{array}{l}\text { Die Zahl der offiziell bestätigten Coronavirus-Infektionen ist in Russland innerhalb der vergangenen } 24 \text { Stun- } \\
\text { den um } 9.039 \text { auf insgesamt 5.035.207 gestiegen. Offiziell gibt es seit Beginn der Pandemie 120.002 Todesfälle. } \\
\text { Den höchsten Zuwachs verzeichnet Moskau mit 3.105 neuen Fällen innerhalb von } 24 \text { Stunden. }\end{array}$ \\
\hline 27.05 .2021 & $\begin{array}{l}\text { Der russische Ministerpräsident Michail Mischustin kündigt in einem Gespräch mit dem belarussischem Minis- } \\
\text { terpräsidenten Roman Golowtschenko an, dass Russland die Verkehrsverbindungen mit Weißrussland ausbaut } \\
\text { und führt als Grund die zuvor in der Corona-Pandemie reduzierten Flüge an. }\end{array}$ \\
\hline 28.05 .2021 & $\begin{array}{l}\text { Die Zahl der offiziell bestätigten Coronavirus-Infektionen ist in Russland innerhalb der vergangenen } 24 \text { Stun- } \\
\text { den um } 9.252 \text { auf insgesamt } 5.044 .459 \text { gestiegen. Offiziell gibt es seit Beginn der Pandemie 120.406 Todesfälle. } \\
\text { Den höchsten Zuwachs verzeichnet Moskau mit 3.274 neuen Fällen innerhalb von } 24 \text { Stunden. }\end{array}$ \\
\hline 28.05 .2021 & $\begin{array}{l}\text { Die Ethikkommission des russischen Gesundheitsministeriums erteilt keine Genehmigung für klinische Stu- } \\
\text { dien eines Coronavirus-Impfstoffs, der Russlands »Sputnik V« und das britische »AstraZeneca« kombinieren soll. }\end{array}$ \\
\hline 29.05 .2021 & $\begin{array}{l}\text { Die Zahl der offiziell bestätigten Coronavirus-Infektionen ist in Russland innerhalb der vergangenen } 24 \text { Stun- } \\
\text { den um } 9.289 \text { auf insgesamt } 5.053 .748 \text { gestiegen. Offiziell gibt es seit Beginn der Pandemie 120.807 Todesfälle. } \\
\text { Den höchsten Zuwachs verzeichnet Moskau mit 3.241 neuen Fällen innerhalb von } 24 \text { Stunden. }\end{array}$ \\
\hline 29.05 .2021 & $\begin{array}{l}\text { Der Gouverneur der Stadt Sewastopol auf der Halbinsel Krim, Michail Raswoschajew, verkündet eine Ver- } \\
\text { längerung des Katastrophenfalls bis 30. Juni. Nach Angaben der Regierung war die Zahl der Fälle von Coro- } \\
\text { navirus-Infektionen zuletzt wieder deutlich gestiegen, von } 25 \text { auf mehr als } 30 \text { Fälle am Tag. Größere Veran- } \\
\text { staltungen bleiben verboten, es besteht weiter Maskenpflicht und chronisch Kranken sowie Schwangeren wird } \\
\text { empfohlen, sich zu isolieren. Das gleiche gilt für den Krai Kolyma im Fernen Osten. Die autonome Republik } \\
\text { Mari El verlängert bis 5. Juli. }\end{array}$ \\
\hline
\end{tabular}




\begin{tabular}{|l|l|}
\hline 30.05 .2021 & $\begin{array}{l}\text { In Russland stecken sich wieder deutlich mehr Menschen mit dem Coronavirus an. Die Zahl der offiziell bestä- } \\
\text { tigten Coronavirus-Infektionen ist in Russland innerhalb der vergangenen 24 Stunden um 9.694 auf insgesamt } \\
\text { 5.063.442 gestiegen. Das ist der höchste Wert seit 19. März. Offiziell gibt es seit Beginn der Pandemie 121.162 } \\
\text { Todesfälle. Den höchsten Zuwachs verzeichnet Moskau mit 3.719 neuen Fällen innerhalb von 24 Stunden. }\end{array}$ \\
\hline 30.05 .2021 & $\begin{array}{l}\text { Der Chef des russischen Gesundheitsministeriums, Michail Muraschko, appelliert an russische Bürger_innen, } \\
\text { sich gegen das Corona-Virus zu impfen und betont, dass es wichtig sei, Herdenimmunität zu erreichen. Etwa elf } \\
\text { Prozent der Menschen in Russland sind zu diesem Zeitpunkt geimpft. Die niedrige Impfquote nennt der Mos- } \\
\text { kauer Bürgermeister Sergej Sobjanin eine »Schande«. Bisher sind im Land vier Coronavirus-Impfstoffe regis- } \\
\text { triert, »Sputnik V«, den es auch in einer Einmal-Impfung gibt, sowie »Gamalea«, »Epivakkorona« und «oviva». }\end{array}$ \\
\hline 30.05 .2021 & $\begin{array}{l}\text { Israel verbietet Reisen nach Russland wegen steigender Covid-19-Infektionen in Russland. Um einreisen zu } \\
\text { dürfen, müssen israelische Staatsbürgerinnen und Staatsbürger eine Sondergenehmigung einholen und sich } \\
\text { nach ihrer Rückkehr für zwei Wochen in Heimquarantäne begeben. }\end{array}$ \\
\hline 30.05 .2021 & $\begin{array}{l}\text { Griechenland verlängert die Einreiseerlaubnis für Russinnen und Russen, die gegen das Coronavirus geimpft, } \\
\text { negativ getestet oder von der Krankheit genesen sind bis 7. Juni. }\end{array}$ \\
\hline
\end{tabular}

Die Zablen der Infizierten in den einzelnen Chronikmeldungen stammen aus Meldungen russischer Medien.

Zusammengestellt von Alena Schwarz und Clara Lipkowski

\section{Mai - 10. Juni 2021}

\begin{tabular}{|c|c|}
\hline 17.05 .2021 & $\begin{array}{l}\text { In der Republik Komi ist eine Erdöl-Pipeline des Konzerns »Lukojl-Komi« leckgeschlagen. Die russische Umwelt- } \\
\text { schutzbehörde »Rosprirodnadsor« schätzt die Größe des entstandenen Ölteppichs auf 1,3 Hektar. Etwa } 100 \\
\text { Tonnen Öl sollen ausgetreten sein, laut der Behörde seien } 9 \text { Tonnen in einen Fluss gelangt. Bereits am 11. Mai } \\
2021 \text { war ein Regenbogenfilm auf dem Fluss Kolwa in Ussinsk entdeckt worden. In der Gemeinde wurde der } \\
\text { Ausnahmezustand ausgerufen, die Ölbohrungen auf dem betreffenden Feld wurden eingestellt. }\end{array}$ \\
\hline 17.05 .2021 & $\begin{array}{l}\text { Der russische Präsident Wladimir Putin verlängert die Amtszeit des Gesandten für den Föderationskreis Nord- } \\
\text { kaukasus, Jurij Tschajka, um ein Jahr. Tschajka, der bis } 2020 \text { leitender Generalstaatsanwalt war, wird am } 21 . \\
\text { Mai } 202170 \text { Jahre alt. Das Gesetz sieht eine Altersgrenze für Staatsbeamte bei } 65 \text { Jahren vor, erlaubt jedoch } \\
\text { die Verlängerung der Dienstzeit durch den Präsidenten. }\end{array}$ \\
\hline 18.05 .2021 & $\begin{array}{l}\text { Nordmazedonien weist einen russischen Diplomaten aus. Dies teilte das nordmazedonische Außenministerium } \\
\text { mit. Die Gründe für die Ausweisung wurden nicht genannt. Russland erwägt spiegelbildliche Maßnahmen. }\end{array}$ \\
\hline 18.05 .2021 & $\begin{array}{l}\text { Die russische Staatsduma nimmt in erster Lesung ein Gesetz an, dass es russischen Staatsbürgern und juris- } \\
\text { tischen Personen verbietet, die Arbeit von in Russland »unerwünschten« Nichtregierungsorganisationen zu } \\
\text { unterstützen oder sich daran zu beteiligen. Auch die Beteiligung an der Arbeit solcher NGOs außerhalb Russ- } \\
\text { lands soll verboten werden. }\end{array}$ \\
\hline 18.05 & $\begin{array}{l}\text { Die russische Staatsduma nimmt in erster Lesung ein Gesetz an, dass es russischen Staatsbürgern, die für Orga- } \\
\text { nisationen arbeiten, die als »extremistisch« eingestuft wurden, über einen Zeitraum von bis zu fünf Jahren ver- } \\
\text { bietet, bei Wahlen zur Staatsduma zu kandidieren. Der Gesetzentwurf sieht vor, dass Bürger, die Mitglieder } \\
\text { öffentlicher oder religiöser Vereinigungen sind, die per Gerichtsentscheid wegen Extremismus oder Terrorismus } \\
\text { geschlossen wurden, vorübergehend nicht in die Duma gewählt werden dürfen. Dies gilt auch für Personen, die } \\
\text { an den Aktivitäten solcher Organisationen beteiligt sind, sei es organisatorischer, beratender oder finanzieller Art. }\end{array}$ \\
\hline 19.05 .2021 & $\begin{array}{l}\text { Der Chefredakteur der Zeitung "Wedomosti«, Andrej Schmarow, verlässt seinen Posten. Seine Nachfolgerin } \\
\text { wird Irina Kasmina, bisher stellvertretende Generaldirektorin bei »Business News Media». Schmarow war im } \\
\text { März } 2020 \text { Nachfolger von Nikolaj Bulawin geworden, nachdem dieser aus Protest gegen einen Eigentümer- } \\
\text { wechsel das Blatt verlassen hatte. }\end{array}$ \\
\hline
\end{tabular}




\begin{tabular}{|c|c|}
\hline 20.05 .2021 & $\begin{array}{l}\text { Der russische Außenminister Sergej Lawrow trifft sich mit seinem US-amerikanischen Amtskollegen Anthony } \\
\text { Blinken in der isländischen Hauptstadt Reykjavik. Beide betonen die Bereitschaft zu einer Verbesserung der } \\
\text { angespannten Beziehung zwischen den Ländern. Blinken brachte außerdem seine Sorge um den Gesundheits- } \\
\text { zustand des inhaftierten Oppositionspolitikers Aleksej Nawalnyj zum Ausdruck. }\end{array}$ \\
\hline 20.05 .2021 & $\begin{array}{l}\text { Der russische Außenminister Sergej Lawrow und sein kanadischer Amtskollege Marc Garneau treffen sich zu } \\
\text { Gesprächen in der isländischen Hauptstadt Reykjavik. Themen sind unter anderem die Arktis, Venezuela und } \\
\text { die Situation in Bergkarabach. Es ist das erste Treffen der beiden Außenminister seit vier Jahren. }\end{array}$ \\
\hline 20.05 .2021 & $\begin{array}{l}\text { Die Außenminister der acht Anrainerstaaten der Arktis bekennen sich zum Klimaschutz. Sie einigten sich bei } \\
\text { einem Treffen auf Maßnahmen zur Bekämpfung der Erderwärmung. Sie wollen insbesondere in den Bereichen } \\
\text { Klima, Umwelt und Wissenschaft kooperieren. Dem Rat gehören neben Russland und den USA auch Kanada, } \\
\text { Norwegen, Dänemark, Schweden, Finnland und Island an. }\end{array}$ \\
\hline 20.05 .2021 & $\begin{array}{l}\text { Der russische Präsident Wladimir Putin droht nach Berichten der Nachrichtenagentur »Interfax« damit, Geg- } \\
\text { nern Russlands »die Zähne auszuschlagen«. Ausländische Mächte versuchten regelmäßig, Russland Gebiete } \\
\text { "wegzuschnappen«, dies ließe sich Russland in Zukunft nicht mehr gefallen. Die Entwicklung des Militärs sei } \\
\text { dafür Garant, wird Putin zitiert. }\end{array}$ \\
\hline 21.05 .2021 & $\begin{array}{l}\text { Der russische Historiker und Leiter des Regionalbüros der Menschenrechtsorganisation »Memorial« in Kare- } \\
\text { lien, Jurij Dmitrijew, erhält den Sacharow-Preis für geistige Freiheit. Dies teilte das »Norwegische Helsinki- } \\
\text { Komitee« mit, das den Preis jährlich verleiht. Dmitrijew ist zurzeit inhaftiert. Er wurde wegen Kinderporno- } \\
\text { graphie schuldig gesprochen. Zurzeit läuft das Berufungsverfahren. }\end{array}$ \\
\hline 22.05 .2021 & $\begin{array}{l}\text { Russische Polizisten unterbrechen einen Kongress kommunaler Politiker_innen in Nischni Nowgorod und } \\
\text { nehmen mehrere Teilnehmende fest, unter ihnen die Moskauer Oppositionspolitikerin, Julia Galjamina. Sie } \\
\text { berichtet aufTwitter von ihrer Verhaftung und der anschließenden Gerichtsverhandlung. Die Polizei begründet } \\
\text { die Festnahmen mit Verstößen gegen Corona-Hygiene-Maßnahmen. Die Teilnehmenden weisen das zurück. }\end{array}$ \\
\hline 22.05 & $\begin{array}{l}\text { Metropolit Hilarion, Leiter der Synodalen Abteilung für kirchliche Außenbeziehungen, regt an, Jagen in der } \\
\text { Freizeit einzuschränken. Außerdem fordert der Vertreter der russisch-orthodoxen Kirche, den Zugang zu Waf- } \\
\text { fen für russische Bürger_innen zu erschweren. Anlass ist die Schießerei, bei der ein 19-Jähriger am 11. Mai } 2021 \\
\text { in Kasan im Gymnasium Nr. } 175 \text { neun Menschen tötete, unter ihnen sieben Kinder und zwei Lehrer. Zwan- } \\
\text { zig Kinder und drei Erwachsene wurden verletzt. }\end{array}$ \\
\hline 23.05 & $\begin{array}{l}\text { Der belarussische Geheimdienst zwingt mit einem Kampfjet ein Flugzeug der Fluglinie Ryanair, das auf dem } \\
\text { Weg von Athen nach Vilnius ist, in Minsk zur Landung. Dabei werden der belarussische Journalist Roman } \\
\text { Protassewitsch und seine Freundin Sofia Sapega, die russische Staatsbürgerin ist, festgenommen. Roman Pro- } \\
\text { tassewitsch ist für den Nachrichtenkanal »Nexta» tätig, der bei den belarussischen Behörden als »extremis- } \\
\text { tisch" geführt wird. Das Flugzeug setzt nach der Zwangslandung seine Reise fort, sechs Reisende, die russi- } \\
\text { sche Staatsbürger sind, fehlen anschließend an Bord. »Nexta« und dem Ryanair-Chef Michael O'Leary zufolge } \\
\text { waren diese offenbar Agenten des russischen Geheimdienstes. }\end{array}$ \\
\hline 23.05 & $\begin{array}{l}\text { Der Sprecher des russischen Präsidenten, Dmitrij Peskow, teilt mit, dass sich Präsident Wladimir Putin und } \\
\text { der ukrainische Präsident Wolodymyr Selenskij auf ein Treffen vorbereiten, bei dem es auch über die Anglie- } \\
\text { derung der ukrainischen Halbinsel Krim an Russland gehen soll. }\end{array}$ \\
\hline 24.05 .2021 & $\begin{array}{l}\text { Nach der Zwangslandung eines Ryanair-Flugzeugs in der belarussischen Hauptstadt Minsk bestätigt die dor- } \\
\text { tige russische Botschaft offiziell, dass auch die Begleiterin des Journalisten Roman Protassewitsch, die russische } \\
\text { Staatsbürgerin Sofia Sapega, verhaftet wurde. Die 23-jährige Jurastudentin sei in das Okrestina-Gefängnis in } \\
\text { Minsk gebracht worden, sagt zudem ihre Mutter Anna Duditsch dem russischen Dienst der BBC. Kritik, der } \\
\text { Konsul habe sich nicht für Sapega eingesetzt, weißt die Botschaft auf Facebook zurück. }\end{array}$ \\
\hline 24.05 .2021 & $\begin{array}{l}\text { Russische Staatsmedien sollen von der Pflicht, Finanzierungsquellen aus dem Ausland kenntlich zu machen, aus- } \\
\text { genommen werden. Einen entsprechenden Gesetzentwurf bereitet das Ministerium für Digitales vor. Einmal im } \\
\text { Quartal müssen russische Medien ihre Finanzquellen offenlegen. Russland gibt an, so den ausländischen Ein- } \\
\text { fluss auf russische Medien sichtbar machen zu wollen. Eine Liste von Ausnahmen regelt, welche Medien davon } \\
\text { befreit sind; diese soll nun entsprechend erweitert werden, meldet die staatliche Nachrichtenagentur Interfax. }\end{array}$ \\
\hline 24.05 .2021 & $\begin{array}{l}\text { Der US-amerikanische Internetkonzern Google klagt gegen die russische Medienaufsichtsbehörde Roskom- } \\
\text { nadsor. Das Unternehmen weigert sich, Links zu mehreren Internetseiten zu löschen. Roskomnadsor teilt mit, } \\
\text { auf diesen würden Minderjährige zur Teilnahme an illegalen Kundgebungen aufgefordert. Die Klage wurde } \\
\text { bereits am 11. Mai von einem Schiedsgericht in Moskau angenommen. }\end{array}$ \\
\hline 24.05 .2021 & $\begin{array}{l}\text { Der kolumbianische Botschafter wird ins russische Außenministerium einbestellt. Zuvor hatte Kolumbien } \\
\text { Russland für Cyberangriffe kritisiert. }\end{array}$ \\
\hline
\end{tabular}




\begin{tabular}{|c|c|}
\hline 25.05 .2021 & $\begin{array}{l}\text { Der russische Präsident Wladimir Putin und der US-amerikanische Präsident Joe Biden einigen sich auf ein } \\
\text { erstes gemeinsames Treffen am 16. Juni in Genf. Bei dem Gipfel der Regierungschefs sollen die Beziehun- } \\
\text { gen der beiden Länder, die Bekämpfung der Corona-Pandemie und regionale Konflikte thematisiert werden. } \\
\text { Joe Biden spricht sich bei einer Pressekonferenz für die Fertigstellung der Gas-Pipeline »North Stream 2«aus. }\end{array}$ \\
\hline 25.05 .2021 & $\begin{array}{l}\text { Die russische Studentin Sofia Sapega ist nach der erzwungenen Landung einer "Ryanair«-Maschine in der bela- } \\
\text { russischen Hauptstadt Minsk weiter in Haft. Der belarussische TV-Sender "Scholtye sliwy« veröffentlicht ein } \\
\text { Video, in dem sie angibt, für den Telegram-Kanal "Schwarzbuch Belarus« verantwortlich zu sein, der Namen } \\
\text { von Mitgliedern des belarussischen Sicherheitsapparates veröffentlicht. Dem russischen TV-Sender "Doschd« } \\
\text { zufolge ist es von belarussischen Sicherheitskräften gedreht worden, das Geständnis wird international als } \\
\text { erzwungen gewertet. Die Sprecherin des russischen Außenministeriums, Maria Sacharowa, teilt mit, die rus- } \\
\text { sische Botschaft in Minsk sei in Kontakt mit belarussischen Behörden. }\end{array}$ \\
\hline 25.05 .2021 & $\begin{array}{l}\text { Gegen den Kremlkritiker Alexej Nawalnyj, der in einem russischen Lager inhaftiert ist, wird ein weiteres } \\
\text { Gerichtsverfahren eingeleitet. Der Nachrichtenagentur Interfax sagte Nawalnyjs Anwältin Olga Michailowa, } \\
\text { derzeit liefen drei Strafverfahren gegen ihn, das neueste wegen Beleidigung eines Richters. Außerdem werden } \\
\text { dem Oppositionspolitiker Veruntreuung von Spenden seiner Anti-Korruptions-Stiftung und die Gründung } \\
\text { einer illegalen Organisation zur Last gelegt. Nawalnyj weist die Anschuldigungen als politisch motiviert zurück. }\end{array}$ \\
\hline 26.05 .2021 & $\begin{array}{l}\text { Mehrere Nichtregierungsorganisationen, darunter die belarussische Menschenrechtsgruppe Wjasna, bezeich- } \\
\text { nen Sofia Sapega als "politische Gefangene« und fordern ihre sofortige Freilassung sowie die des belarussischen } \\
\text { Journalisten Roman Protassewitsch, mit dem Sapega am 23. Mai } 2021 \text { festgenommen worden war. }\end{array}$ \\
\hline 26.05 .2021 & $\begin{array}{l}\text { Die Oppositionspolitikerin Julia Galjamina wird nach ihrer Teilnahme an einem Kongress regionaler Politiker } \\
\text { in Nischni Nowgorod zu sieben Tagen Lagerhaft verurteilt, weitere Teilnehmende zu Geldstrafen und Arrest. } \\
\text { Die Polizei hatte die Veranstaltung mit der Begründung aufgelöst, es sei gegen Corona-Hygiene-Maßnahmen } \\
\text { verstoßen worden. Die Teilnehmenden hatten dies zurückgewiesen. }\end{array}$ \\
\hline 26.05 .2021 & $\begin{array}{l}\text { Die russische Regierung stuft drei deutsche Nichtregierungsorganisationen als unerwünscht ein, damit gilt fak- } \\
\text { tisch ein Betätigungsverbot. Betroffen sind das »Forum Russischsprachiger Europäer«, das »Zentrum für Libe- } \\
\text { rale Moderne« und der »Verein Deutsch-Russischer Austausch«, letztere sind Mitglieder im Petersburger Dialog, } \\
\text { einem Gesprächsforum mit deutscher Beteiligung, das für den 14. und 15. Oktober in der russischen Exklave } \\
\text { Kaliningrad geplant ist. Der deutsche Außenminister Heiko Maas verurteilt den Schritt als »herben Rückschlag } \\
\text { für unsere Bemühungen, ein besseres Verhältnis zu Russland zu erreichen.» }\end{array}$ \\
\hline 27.05 . & $\begin{array}{l}\text { Russland streicht zwei Flüge von Austrian Airlines und Air France, die von Wien und Paris in die russische } \\
\text { Hauptstadt Moskau über Belarus geplant waren. Die österreichischen Behörden fordern von Russland eine Klar- } \\
\text { stellung. Ein Teil der Passagiere des Air-France-Fluges wird von der staatlichen russischen Fluglinie Aeroflot } \\
\text { befördert. Hintergrund ist die Entscheidung der Europäischen Union, den Luftraum über Belarus für Flugge- } \\
\text { sellschaften mit Sitz in der EU zu schließen, nachdem in der belarussischen Hauptstadt Minsk eine Maschine } \\
\text { der Fluglinie »Ryanair« zwangslanden musste. }\end{array}$ \\
\hline 27.05 .2021 & $\begin{array}{l}\text { Das Amtsgericht des Moskauer Bezirks Taganskij verurteilt den Kurznachrichtendienst Twitter zu einer Geld- } \\
\text { strafe von } 19 \text { Millionen Rubel (etwa } 213.000 \text { Euro), weil Aufrufe zu unangemeldeten Veranstaltungen nicht } \\
\text { gelöscht worden waren. Ebenso muss die Video-Plattform TikTok 1,5 Millionen Rubel (etwa 17.000 Euro) für } \\
\text { nicht gelöschte Inhalte, der Internetkonzern Google 3,5 Millionen Rubel (knapp } 40.000 \text { Euro) für fehlende } \\
\text { Filter bei Suchergebnissen zahlen. }\end{array}$ \\
\hline 27.05 .2021 & $\begin{array}{l}\text { Die belarussische Menschenrechtsorganisation "Wjasna« teilt mit, dass der russischen Jura-Studentin Sofia } \\
\text { Sapega, die mit ihrem Freund, dem belarussischen Journalisten Roman Protassewitsch in Minsk verhaftet } \\
\text { wurde, bis zu zwölf Jahre Haft drohen. Ihr werde Aufstachelung zum Rassen-, nationalen, religiösen oder ande- } \\
\text { ren sozialen Umsturz vorgeworfen. Der Kreml erklärt, dass er die Auslieferung Sapegas nach Russland prüfe. }\end{array}$ \\
\hline 27.05 .2021 & $\begin{array}{l}\text { Die oppositionelle Organisation »Offenes Russland« löst sich auf. Der Vorsitzende Andrej Piwowarow gibt als } \\
\text { Grund den zunehmenden staatlichen Druck an. Man wolle so neue Geldbußen und Strafverfahren vermeiden } \\
\text { und die eigenen Unterstützer schützen. Die Organisation wurde } 2001 \text { von dem mittlerweile im Ausland leben- } \\
\text { den Kremlkritiker Michail Chodorkowski mitgegründet und war von der russischen Generalstaatsanwaltschaft } \\
\text { als »unerwünschte Organisation« eingestuft worden. }\end{array}$ \\
\hline 28.05 .2021 & $\begin{array}{l}\text { Mit einem Tag Verspätung startet die russische Weltraumrakete »Sojus } 2.1 \text { b« ins Weltall. Die Rakete sollte } 36 \\
\text { Kommunikationssatelliten der britischen Firma »OneWeb« vom russischen Weltraumbahnhof »Kosmodrom } \\
\text { Wostotschny« nahe der chinesischen Grenze in die Umlaufbahn bringen. Der Start war am Vortag wegen tech- } \\
\text { nischer Probleme verschoben worden. }\end{array}$ \\
\hline 28.05 .2021 & $\begin{array}{l}\text { Der russische Präsident Wladimir Putin hält per Videokonferenz ein operatives Treffen mit ständigen Mitglie- } \\
\text { dern des russischen Sicherheitsrats ab. Thema ist die nationale Sicherheitsstrategie der Russischen Föderation. }\end{array}$ \\
\hline
\end{tabular}




\begin{tabular}{|c|c|}
\hline 28.05 .2021 & $\begin{array}{l}\text { Der russische Präsident Wladimir Putin trifft sich in der südrussischen Stadt Sotschi am Schwarzen Meer mit } \\
\text { dem belarussischen Präsidenten Aljaksandr Lukaschenka. Er sichert Belarus finanzielle Unterstützung in Höhe } \\
\text { von } 500 \text { Millionen US-Dollar (etwa } 400 \text { Millionen Euro) bis Ende Juni } 2021 \text { zu. Die Summe ist dem Sprecher } \\
\text { des russischen Präsidenten, Dmitrij Peskow, zufolge die zweite Tranche eines Kredits, der bereits vor der inter- } \\
\text { national kritisierten Zwangslandung eines Ryanair-Flugzeugs in Minsk beschlossen worden war. Putin kriti- } \\
\text { siert bei dem Treffen, dass die EU »emotional« auf die Zwangslandung reagiert habe. Putin betont bei dem } \\
\text { Treffen, dass er Belarus unterstütze. }\end{array}$ \\
\hline 28.05 .2021 & $\begin{array}{l}\text { Der US-Softwarekonzern Microsoft meldet einen Cyberangriff mutmaßlich russischer Hacker in den USA } \\
\text { und mindestens } 23 \text { weiteren Ländern. Auf etwa 3.000 E-Mail-Konten bei mehr als } 150 \text { verschiedenen Orga- } \\
\text { nisationen habe es Zugriffe gegeben. }\end{array}$ \\
\hline 28.05 .2021 & $\begin{array}{l}\text { Fünf Polizisten, denen im Fall des Journalisten Iwan Golunow Beweisfälschung vorgeworfen wurde, werden am } \\
\text { Moskauer Stadtgericht verurteilt. Der Hauptangeklagte Igor Ljachowez muss zwölf Jahre ins Gefängnis, drei } \\
\text { weitere jeweils für acht Jahre und ein Ex-Polizist für fünf Jahre. Jeder von ihnen muss Golunow eine Million } \\
\text { Rubel (etwa } 11.000 \text { Euro) Entschädigung zahlen. Der Investigativjournalist war im Juni } 2019 \text { unter dem Vor- } \\
\text { wurf des Drogenhandels festgenommen worden. Russische und internationale Medien sowie Menschenrechts- } \\
\text { organisationen hatten dies heftig kritisiert. Nach wenigen Tagen kam Golunow überraschend frei. }\end{array}$ \\
\hline 29.05 .2021 & $\begin{array}{l}\text { Am zweiten Tag eines Treffens zwischen dem russischen Präsidenten Wladimir Putin und dem belarussischen } \\
\text { Präsidenten Aljaksandr Lukaschenka spricht Putin Angaben des Kremls zufolge die Situation der russischen } \\
\text { Staatsbürgerin Sofia Sapega an. Die Studentin war zusammen mit ihrem Partner, dem belarussischen Journa- } \\
\text { listen Roman Protassewitsch, verhaftet worden. Bei dem Treffen einigen sich Putin und Lukaschenka darauf, } \\
\text { Routen der staatlichen belarussischen Fluglinie Belavia in russische Städte wiederaufzunehmen. Diese waren } \\
\text { demnach während der Corona-Pandemie reduziert worden. }\end{array}$ \\
\hline 29.05 .2021 & $\begin{array}{l}\text { Die französische Fluglinie Air France und die deutsche Fluggesellschaft Lufthansa einigen sich mit Moskau } \\
\text { auf einen Flugplan unter Umgehung von Belarus. }\end{array}$ \\
\hline 29.05 .2021 & $\begin{array}{l}\text { Russland bietet Belarus Hilfe dabei an, in der EU gestrandete Flugreisende nach Hause zu bringen. Hinter- } \\
\text { grund ist, dass die Europäische Union den Luftraum über Belarus meidet, seit ein Flugzeug in Minsk zur Lan- } \\
\text { dung gezwungen wurde, um den belarussischen Journalisten Roman Protassewitsch und seine Freundin Sofia } \\
\text { Sapega festzunehmen. }\end{array}$ \\
\hline 29.05 .2021 & $\begin{array}{l}\text { Der russische Ministerpräsident Michail Mischustin teilt mit, dass die Regierung eine Gesetzesänderung geneh- } \\
\text { migt hat, die vorsieht, Geldstrafen zu verhängen, wenn Anbieter von Kunden beim Kauf von Waren und Dienst- } \\
\text { leistungen nicht notwendige Kundendaten sammeln. Telefonnummern, E-Mail-Adressen, Führerscheindaten } \\
\text { und andere persönliche Informationen sollen so geschützt werden. }\end{array}$ \\
\hline 30.05 .2021 & $\begin{array}{l}\text { Der belarussische Außenminister Wladimir Makei sagt in einem Interview mit der russischen Zeitung Kom- } \\
\text { mersant, der belarussische Präsident Aljaksandr Lukaschenka könne die russische Staatsbürgerin Sofia Sapega } \\
\text { begnadigen oder sie zur Verbüßung ihrer Strafe nach Russland ausliefern. }\end{array}$ \\
\hline 02.06 .2021 & $\begin{array}{l}\text { Die deutsche "Lufthansa« annulliert mehrere Flüge aufgrund fehlender Genehmigungen der russischen Luft- } \\
\text { fahrtbehörde. Als Reaktion darauf teilt auch das deutsche Luftfahrt-Bundesamt mit, bis auf Weiteres keine } \\
\text { Genehmigungen mehr für Flüge russischer Airlines zu erteilen. Dem vorausgegangen war die Aussetzung des } \\
\text { Linienflugverkehrs von russischer Seite im März 2020. Seitdem würde die Fluggenehmigung auf monatlicher } \\
\text { Basis erteilt, teilte das deutsche Verkehrsministerium mit. Es kündigte an, Flüge russischer Airlines wieder } \\
\text { zu gestatten, sobald Lufthansa die erforderliche Genehmigung von russischer Seite erhalten habe. Am späten } \\
\text { Nachmittag teilte Lufthansa mit, die Genehmigungen erhalten zu haben. Die Genehmigung der deutschen } \\
\text { Behörden folgte kurze Zeit später. }\end{array}$ \\
\hline 02.06 .2021 & $\begin{array}{l}\text { Das russische Justizministerium setzt drei deutsche Nichtregierungsorganisationen auf die Liste sogenannter } \\
\text { "unerwünschter Organisationen«. Die Aktivitäten des "Forum russischsprachiger Europäer e. V.«, des "Zen- } \\
\text { trum für liberale Moderne» sowie des "Deutsch-Russische Austausch e. V.« werden als »Bedrohung für die ver- } \\
\text { fassungsmäßige Ordnung und Sicherheit der Russischen Föderation« angesehen. }\end{array}$ \\
\hline 03.06 .2021 & $\begin{array}{l}\text { In einem offenen Brief gibt das unabhängige Medium »Vtimes« seine Schließung zum 12. Juni } 2021 \text { bekannt. } \\
\text { Ende Mai } 2021 \text { war »Vtimes« vom Justizministerium auf die Liste sogenannter »ausländischer Agenten« gesetzt } \\
\text { worden. Das Medium erklärt die Schließung mit der drohenden Verfolgung durch die russische Justiz. Außer- } \\
\text { dem schrecke das Stigma des »ausländischen Agenten« Werbekunden ab und stelle das Medium zu Unrecht } \\
\text { in eine Ecke der politischen Opposition. "Vtimes« war erst im Juni } 2020 \text { gegründet worden, nachdem die } \\
\text { Redaktion der Zeitung "Vedomosti» nach einem Eigentümer- und damit verbundenen Chefredakteurswech- } \\
\text { sel geschlossen gekündigt hatte. }\end{array}$ \\
\hline
\end{tabular}




\begin{tabular}{|c|c|}
\hline 06.06 .2021 & $\begin{array}{l}\text { Dmitrij Gudkow, Oppositionspolitiker und von } 2011 \text { bis } 2016 \text { Abgeordneter der Staatsduma verlässt Russ- } \\
\text { land nach eigenen Angaben aufgrund eines gegen ihn laufenden Strafverfahrens. Gudkow war am 01. Juni } \\
2021 \text { festgenommen worden. Gegen ihn läuft ein Verfahren wegen der Verursachung von Eigentumsschäden. } \\
\text { Er soll in den Jahren } 2015 \text { bis } 2017 \text { Räumlichkeiten angemietet haben, für die er die Miete in Höhe von rund } \\
\text { einer Million Rubel (etwa } 11.000 \text { Euro) schuldig geblieben ist. Eigenen Angaben zufolge betrifft diese Ange- } \\
\text { legenheit die Firma von Gudkows Eltern. }\end{array}$ \\
\hline 07.06 .2021 & $\begin{array}{l}\text { Der russische Präsident Wladimir Putin unterzeichnet ein Gesetz zum Ausstieg Russlands aus dem sogenann- } \\
\text { ten »Vertrag über den offenen Himmel« (»Open Skies Treaty»). Dieser regelt seit } 2002 \text { internationale militäri- } \\
\text { sche Beobachtungsflüge über fremden Staatsgebieten. Die USA waren im Mai } 2021 \text { endgültig von dem Abkom- } \\
\text { men zurückgetreten. }\end{array}$ \\
\hline 07.06 .2021 & $\begin{array}{l}\text { Wadim Kobsew, Anwalt des russischen Oppositionspolitikers Aleksej Nawalnyj, gibt dessen Entlassung aus dem } \\
\text { Gefängniskrankenhaus und erneute Verlegung in die "Strafkolonie Nr. } 2 \text { «ekannt. Nawalnyj war im April ins } \\
\text { Krankenhaus verlegt worden, nachdem er Ende März in einen Hungerstreik getreten war, mit dem er ange- } \\
\text { messene medizinische Versorgung gefordert hatte. Nawalnyj sitzt zurzeit eine Anfang Februar } 2021 \text { vom Simo- } \\
\text { nowskij-Bezirksgericht in Moskau angeordnete Haftstrafe ab. Ihm wird der Verstoß gegen Bewährungsaufla- } \\
\text { gen im Zusammenhang mit seiner Verurteilung im sogenannten »Fall Yves Rocher« im Jahr } 2014 \text { vorgeworfen. }\end{array}$ \\
\hline 07.06 .2021 & $\begin{array}{l}\text { Der städtische Abgeordnete des Moskauer Bezirks Krasnoselskij, Ilja Jaschin reicht gemeinsam mit mehreren } \\
\text { anderen eine Sammelklage ein gegen die russische Medienaufsichtsbehörde "Roskomnadsor» wegen der im } \\
\text { März } 2021 \text { erfolgten Drosselung des Kurznachrichtendienstes "Twitter«. Mit ihrer Klage wollen sie die Aufhe- } \\
\text { bung der Drosselung erreichen sowie die Streichung des Dienstes von der Liste der Dienste, die die Stabilität, } \\
\text { Sicherheit und Integrität des Internets in Russland bedrohten. }\end{array}$ \\
\hline 07.06 .2021 & $\begin{array}{l}\text { Das Twerskoj-Bezirksgericht in Moskau verlängert den eingeschränkten Hausarrest der Anwältin des von } \\
\text { Oppositionspolitiker Aleksej Nawalnyj gegründeten "Fonds für Korruptionsbekämpfung» (FBK), Ljubow } \\
\text { Sobol, um weitere sechs Monate. Dieser war im Februar wegen der Verletzung epidemiologischer Vorschriften } \\
\text { im Zusammenhang mit einer nicht genehmigten Kundgebung zur Unterstützung Nawalnyjs am 23. Januar } \\
2021 \text { verhängt worden. }\end{array}$ \\
\hline 07.06 .2021 & $\begin{array}{l}\text { Das Twerskoj-Bezirksgericht verlängert den eingeschränkten Hausarrest von Oleg Nawalnyj, Bruder des inhaf- } \\
\text { tierten Oppositionspolitikers Aleksej Nawalnyj, um sechs Monate. Der Hausarrest war im Februar wegen des } \\
\text { Verstoßes gegen epidemiologische Vorschriften im Zusammenhang mit einer nicht genehmigten Kundgebung } \\
\text { zur Unterstützung Aleksej Nawalnyjs am 23. Januar } 2021 \text { verhängt worden. }\end{array}$ \\
\hline 08.06 .2021 & $\begin{array}{l}\text { Der Europäische Gerichtshof für Menschenrechte spricht Iwan Nepomnjaschtschij 7.500 Euro Entschädigung } \\
\text { zu. Nepomnjaschtschij war wegen seiner Teilnahme am sogenannten »Marsch der Millionen« am 06. Mai } 2012 \\
\text { auf dem Moskauer Bolotnaja-Platz vom Moskauer Samoskworetskij-Bezirksgericht zu zweieinhalb Jahren Haft } \\
\text { verurteilt worden. Der Europäische Gerichtshof für Menschenrechte befand diese Strafe für unverhältnismä- } \\
\text { Big. Sie habe möglicherweise abschreckend auf andere Protestierende gewirkt. }\end{array}$ \\
\hline 08.06 .2021 & $\begin{array}{l}\text { Andrej Piwowarow, ehemaliger Direktor der am 27. Mai } 2021 \text { aufgelösten Menschenrechtsorganisation »Otkry- } \\
\text { taja Rossija» (dt. "Offenes Russland«) wird wegen der Durchführung von Aktivitäten einer sogenannten »uner- } \\
\text { wünschten Organisation« angeklagt. Piwowarow war am 31. Mai } 2021 \text { festgenommen worden und sitzt seitdem } \\
\text { in Untersuchungshaft. »Otkrytaja Rossija« war im Jahr } 2017 \text { als »unerwünschte Organisation« eingestuft worden. }\end{array}$ \\
\hline 09.06 .2021 & $\begin{array}{l}\text { Die russische Staatsduma verabschiedet in dritter und letzter Lesung ein Gesetz, dass es russischen Bürgern und } \\
\text { juristischen Personen aus der ganzen Welt verbietet, sich an der Arbeit sogenannter »unerwünschter Organisatio- } \\
\text { nen« zu beteiligen. Das Gesetz enthält außerdem einen Passus, in dem auch ausländische NGOs als unerwünscht } \\
\text { erklärt werden, die sich an Geldtransfers für in Russland ansässige unerwünschte Organisationen beteiligen. }\end{array}$ \\
\hline 09.06 .2021 & $\begin{array}{l}\text { Das Moskauer Stadtgericht erklärt den von Oppositionspolitiker Aleksej Nawalnyj gegründeten »Fonds für Kor- } \\
\text { ruptionsbekämpfung« (FBK) für extremistisch und verbietet die Organisation mit sofortiger Wirkung. Voraus- } \\
\text { gegangen war eine Klage der Moskauer Staatsanwaltschaft. Der FBK schaffe unter dem Deckmantel liberaler } \\
\text { Parolen Bedingungen für die Destabilisierung der sozialen und politischen Ordnung. Bereits im April war der } \\
\text { FBK aufgefordert worden, für die Dauer des Verfahrens seine Tätigkeiten einzustellen. }\end{array}$ \\
\hline 09.06 .2021 & $\begin{array}{l}\text { Das auf Justizfälle spezialisierte Schweizer Medium "Gotham City« berichtet über die Festnahme des russi- } \\
\text { schen Unternehmers Wladislaw Kljuschin in der Schweiz am 21. März 2021. Der Grund für die Festnahme ist } \\
\text { ein Auslieferungsersuchen des US-amerikanischen Bundesstaates Massachusetts. Die US-amerikanische Jus- } \\
\text { tiz wirft Kljuschin Insiderhandel in zweistelliger Millionenhöhe vor. Kljuschin ist Inhaber von "M13 - die } \\
\text { Firma beobachtet und analysiert im Auftrag des Kreml Medien. }\end{array}$ \\
\hline
\end{tabular}




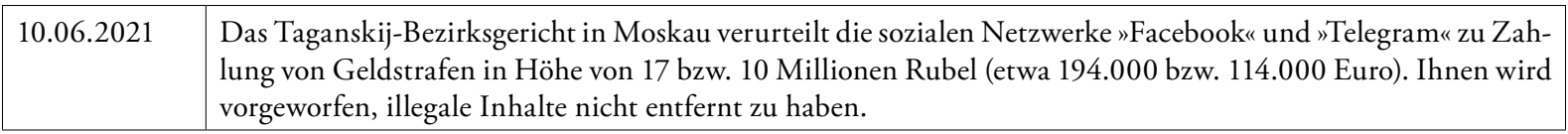

Die Chronik wird zeitnah erstellt und basiert ausschließlich auf im Internet frei zugänglichen Quellen. Die Redaktion der RusslandAnalysen kann keine Gewähr für die Richtigkeit der Angaben übernehmen.

Zusammengestellt von Alena Schwarz und Clara Lipkowski

Sie können die gesamte Chronik seit 2003 (zusätzlich gibt es eine Kurzchronik für die Sowjetunion ab 1964 bzw. Russland ab 1992) auch auf http://www.laender-analysen.de/russland/ unter dem Link "Chronik« lesen.

Herausgeber:

Forschungsstelle Osteuropa an der Universität Bremen Deutsche Gesellschaft für Osteuropakunde e.V. Deutsches Polen-Institut Leibniz-Institut für Agrarentwicklung in Transformationsökonomien Leibniz-Institut für Ost- und Südosteuropaforschung Zentrum für Osteuropa- und internationale Studien (Z0iS) gGmbH

Redaktion:

Anastasia Stoll (verantwortlich)

Chronik: Alena Schwarz

Satz: Matthias Neumann

Wissenschaftlicher Beirat:

Dr. Sabine Fischer, Stiftung Wissenschaft und Politik, Berlin

Prof. Dr. Alexander Libman, Freie Universität Berlin

Prof. Dr. Jeronim Perović, Universität Zürich

Dr. Cindy Wittke, Leibniz-Institut für Ost- und Südosteuropaforschung Regensburg

Die Meinungen, die in den Russland-Analysen geäußert werden, geben ausschließlich die Auffassung der Autoren wieder.

Abdruck und sonstige publizistische Nutzung sind nach Rücksprache mit der Redaktion gestattet.

Russland-Analysen-Layout: Cengiz Kibaroglu, Matthias Neumann und Michael Clemens

Alle Ausgaben der Russland-Analysen sind mit Themen- und Autorenindex archiviert unter www.laender-analysen.de

Die Russland-Analysen werden im Rahmen eines Lizenzvertrages in das Internetangebot der Bundeszentrale für politische Bildung (www.bpb.de) aufgenommen.

ISSN 1613-3390 @ 2021 by Forschungsstelle Osteuropa an der Universität Bremen

Forschungsstelle Osteuropa • Länder-Analysen • Klagenfurter Str. 8 • 28359 Bremen • Telefon: +49 421-218-69600 • Telefax: + 49 421-218-69607

e-mail: laender-analysen@uni-bremen.de•Internet-Adresse: http://www.laender-analysen.de/russland/ 
LÄNDER-ANALYSEN

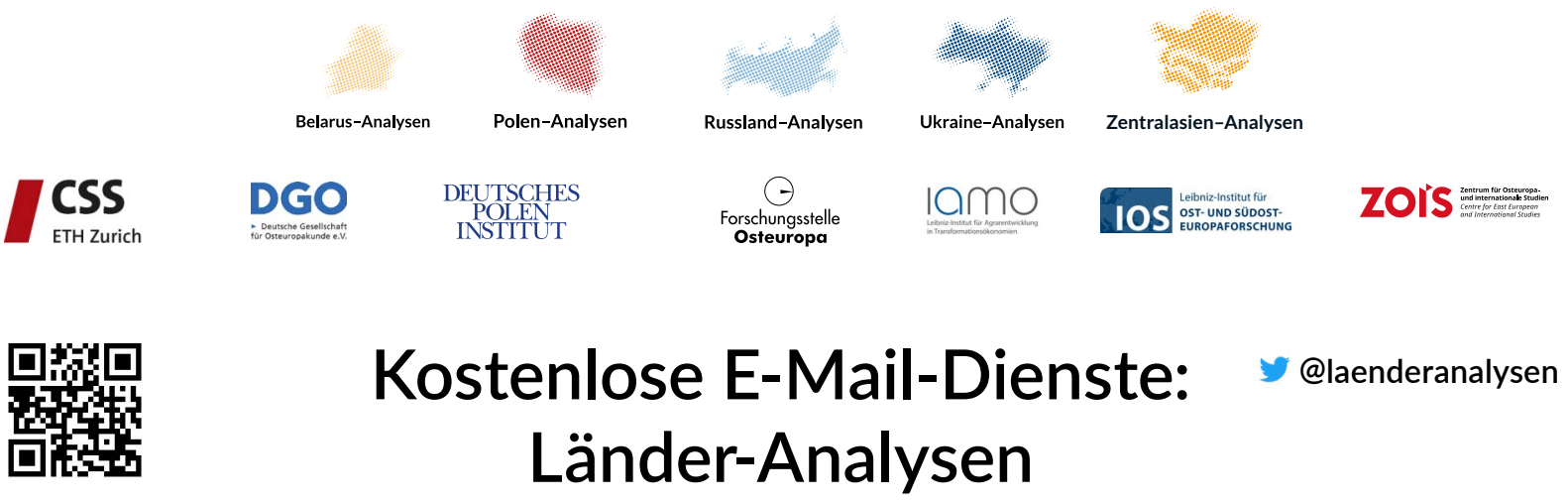

Die Länder-Analysen bieten regelmäßig im kostenlosen Abonnement kompetente Einschätzungen aktueller politischer, wirtschaftlicher, sozialer und kultureller Entwicklungen in Ostmitteleuropa und der GUS. Alle Länder-Analysen verstehen sich als Teil eines gemeinsamen Projektes, das der wissenschaftlich fundierten, allgemeinverständlich formulierten Analyse der Entwicklungen im östlichen Europa, der Offenheit für verschiedene inhaltliche Positionen und der kostenlosen und nicht-kommerziellen Information einer breit verstandenen interessierten Öffentlichkeit verpflichtet ist. Autor/innen sind internationale Fachwissenschaftler/innen und Expert/innen. Die Redaktionen der Länder-Analysen bestehen aus Wissenschaftler/innen mit langjähriger Forschungserfahrung.

Die deutschsprachigen Länder-Analysen werden gemeinsam von der Forschungsstelle Osteuropa an der Universität Bremen, dem Zentrum für Osteuropa- und internationale Studien, der Deutschen Gesellschaft für Osteuropakunde, dem Deutschen Polen-Institut, dem Leibniz-Institut für Agrarentwicklung in Transformationsökonomien und dem Leibniz-Institut für Ost- und Südosteuropaforschung herausgegeben. Die englischsprachigen Länder-Analysen erscheinen in Kooperation der Forschungsstelle Osteuropa mit dem Center for Security Studies (CSS) der ETH Zürich.

Die Länder-Analysen bieten regelmäßig Kurzanalysen zu aktuellen Themen, ergänzt um Grafiken und Tabellen sowie Dokumentationen. Zusätzlich gibt es eine Chronik aktueller Ereignisse.

\section{Belarus-Analysen}

Erscheinungsweise: zweimonatlich

Abonnement unter: http://www.laender-analysen.de/belarus/

\section{Caucasus Analytical Digest}

In englischer Sprache. Erscheinungsweise: zweimonatlich

Abonnement unter: http://www.css.ethz.ch/en/publications/cad.html

\section{Polen-Analysen}

Erscheinungsweise: zweimal monatlich

Abonnement unter: http://www.deutsches-polen-institut.de/newsletter/polen-analysen/

\section{Russland-Analysen}

Erscheinungsweise: zweimal monatlich

Abonnement unter: http://www.laender-analysen.de/russland/

\section{Russian Analytical Digest}

In englischer Sprache. Erscheinungsweise: zweimal monatlich

Abonnement unter: http://www.css.ethz.ch/en/publications/rad.html

\section{Ukraine-Analysen}

Erscheinungsweise: zweimal monatlich

Abonnement unter: http://www.laender-analysen.de/ukraine/

\section{Zentralasien-Analysen}

Erscheinungsweise: zweimonatlich

Abonnement unter: http://www.laender-analysen.de/zentralasien/ 